RESEARCH

SERIES

NUMBER 77

February 2019

\section{VALUING COMMUNITY DEVELOPMENT THROUGH THE SOCIAL INCLUSION PROGRAMME (SICAP) 2015-2017 TOWARDS A FRAMEWORK FOR EVALUATION}

ADELE WHELAN, SEAMUS MCGUINNESS AND JUDITH DELANEY

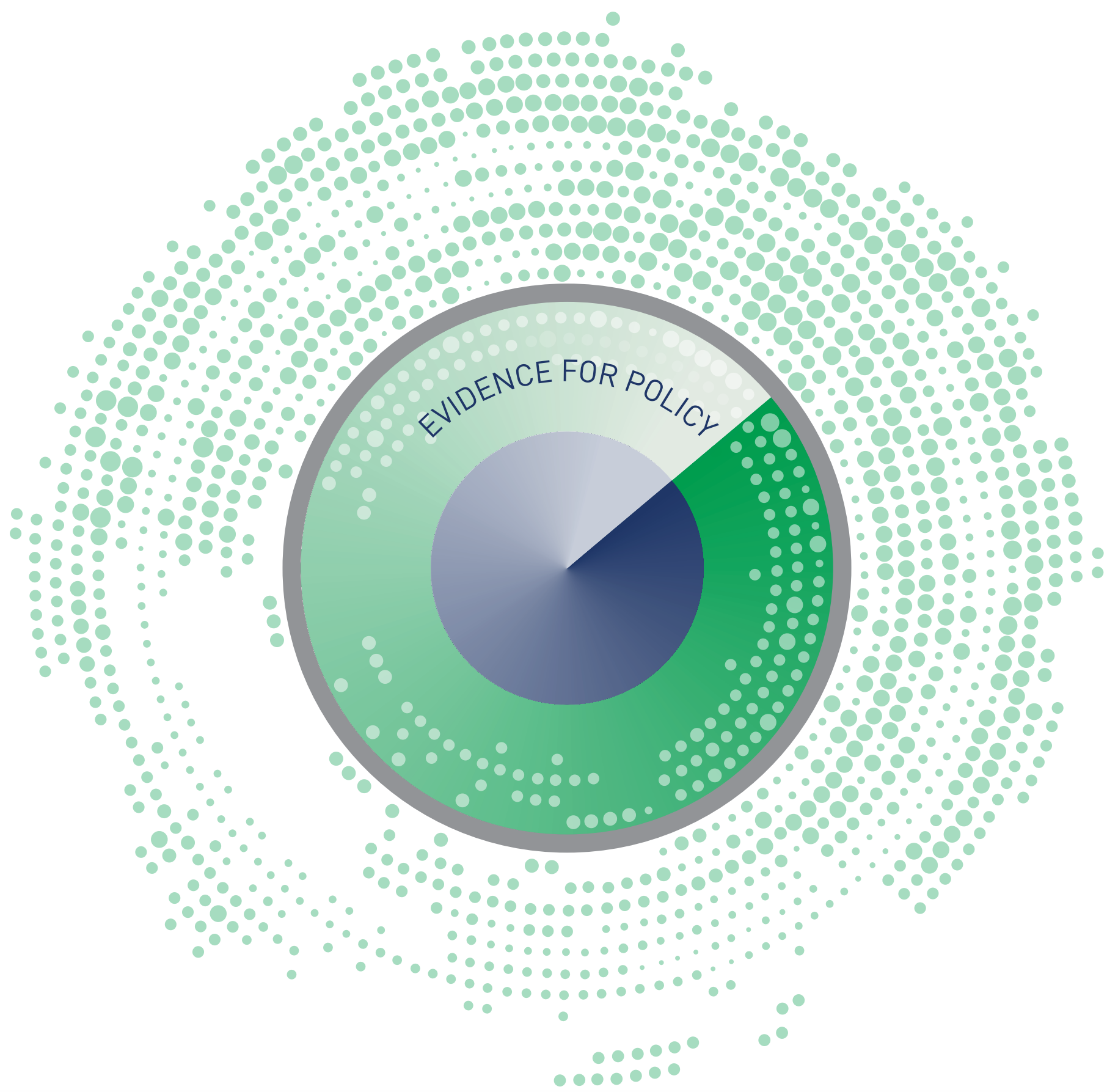




\title{
VALUING COMMUNITY DEVELOPMENT THROUGH THE SOCIAL INCLUSION PROGRAMME (SICAP) 2015-2017: TOWARDS A FRAMEWORK FOR EVALUATION
}

\author{
Adele Whelan \\ Seamus McGuinness \\ Judith Delaney
}

February 2019

RESEARCH SERIES

NUMBER 77

Available to download from www.esri.ie

(c) The Economic and Social Research Institute

Whitaker Square, Sir John Rogerson's Quay, Dublin 2

ISBN 978-0-7070-0468-6

DOI: https://doi.org/10.26504/rs77

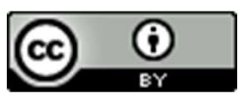

This Open Access work is licensed under a Creative Commons Attribution 4.0 International License (https://creativecommons.org/licenses/by/4.0/), which permits unrestricted use, distribution, and reproduction in any medium, provided the original work is properly credited. 


\section{ABOUT THE ESRI}

The mission of the Economic and Social Research Institute is to advance evidencebased policymaking that supports economic sustainability and social progress in Ireland. ESRI researchers apply the highest standards of academic excellence to challenges facing policymakers, focusing on 12 areas of critical importance to 21st Century Ireland.

The Institute was founded in 1960 by a group of senior civil servants led by Dr T.K. Whitaker, who identified the need for independent and in-depth research analysis to provide a robust evidence base for policymaking in Ireland.

Since then, the Institute has remained committed to independent research and its work is free of any expressed ideology or political position. The Institute publishes all research reaching the appropriate academic standard, irrespective of its findings or who funds the research.

The quality of its research output is guaranteed by a rigorous peer review process. ESRI researchers are experts in their fields and are committed to producing work that meets the highest academic standards and practices.

The work of the Institute is disseminated widely in books, journal articles and reports. ESRI publications are available to download, free of charge, from its website. Additionally, ESRI staff communicates research findings at regular conferences and seminars.

The ESRI is a company limited by guarantee, answerable to its members and governed by a Council, comprising 14 members who represent a cross-section of ESRI members from academia, civil services, state agencies, businesses and civil society. The Institute receives an annual grant-in-aid from the Department of Public Expenditure and Reform to support the scientific and public interest elements of the Institute's activities; the grant accounted for an average of 30 per cent of the Institute's income over the lifetime of the last Research Strategy. The remaining funding comes from research programmes supported by government departments and agencies, public bodies and competitive research programmes.

Further information is available at www.esri.ie 


\section{THE AUTHORS}

Adele Whelan is a Research Officer, Seamus McGuinness is a Research Professor, and Judith Delaney is a Post-Doctoral Research Fellow at the Economic and Social Research Institute. All members of the research team have adjunct research positions at Trinity College Dublin.

\section{ACKNOWLEDGEMENTS}

The work carried out in this report was funded by the Department of Rural and Community Development (DRCD) and managed in conjunction with Pobal as part of the Research Programme on Community Development and Social Inclusion. We would like to thank all the individuals within Pobal who provided assistance during the project, particularly Denis Leamy, Jerry Murphy, Martin Quigley, Richard Deane, Ela Hogan, Lucy Pyne, Maria Farry, Catherine Sheehan and Rebecca McCarthy. Valuable contributions were made by members of the Research Programme Steering Committee: Richard Deane, Paul Geraghty, Clodagh McDonald, Jerry Murphy, Philip O'Connell and Martin Quigley. We would like to thank all the individuals who participated in the SICAP Stakeholder Advisory Panel meetings: Sinead Carr, Bernie Doherty, Allan Farrell, Bryan Fields, Oonagh McCardle, Alan McGrath, John Orme, Ciaran Reid, Cormac Shaw, Kathleen Stack and John Stewart. We would like to thank all the facilitators who summarised the main points from each of the workshop discussions. Also thanks to Conor Ryan for his helpful written submissions. Finally, our thanks go to the Director of the Economic and Social Research Institute (ESRI), an external referee and two internal ESRI referees for their comments on earlier drafts of this report.

This report has been accepted for publication by the Institute, which does not itself take institutional policy positions. All ESRI Research Series reports are peer reviewed prior to publication. The author(s) are solely responsible for the content and the views expressed. 



\section{CONTENTS}

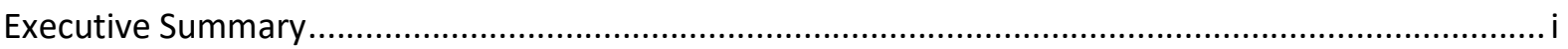

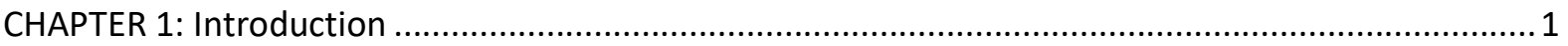

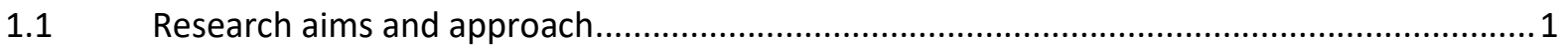

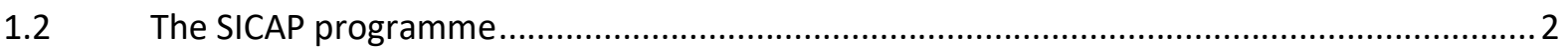

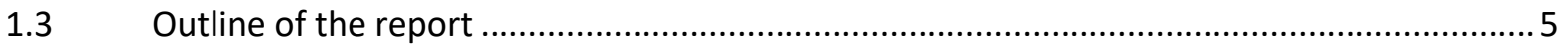

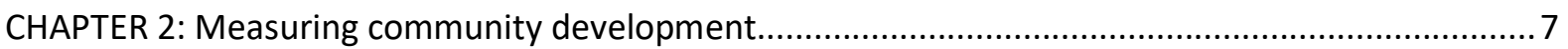

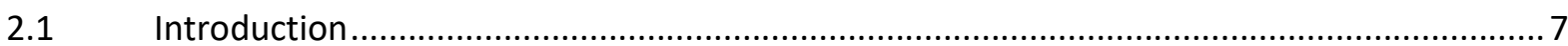

2.2 Conceptual approaches to measuring community development .......................................

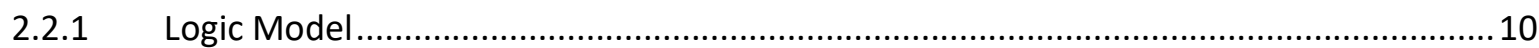

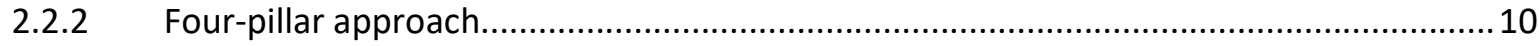

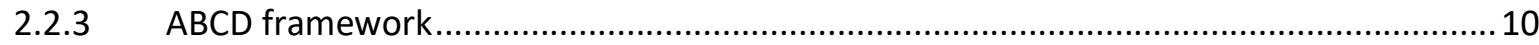

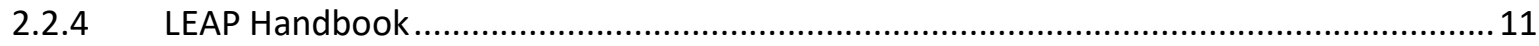

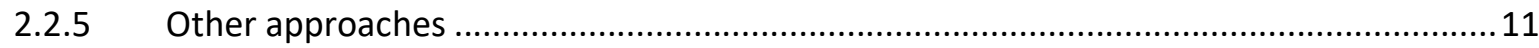

2.3 Metrics suggested in the literature for the measurement of community development......12

2.4 Data currently collected by SICAP that could potentially be incorporated into a

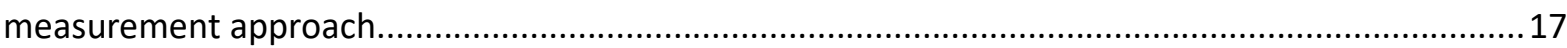

$2.5 \quad$ Input/Activity metrics at an area level collected by SICAP ................................................. 19

2.6 Can metrics currently captured under SICAP be improved?...............................................20

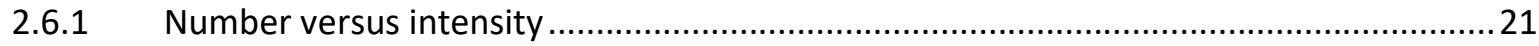

2.6.2 Balance between qualitative and quantitative outcomes ............................................21

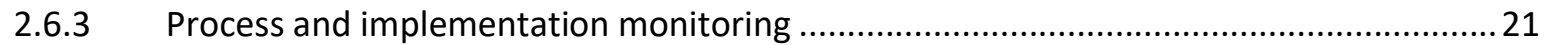

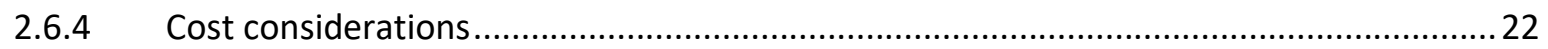

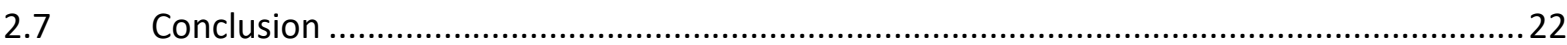

CHAPTER 3: Qualitative research: feedback from consultative workshops .......................................22

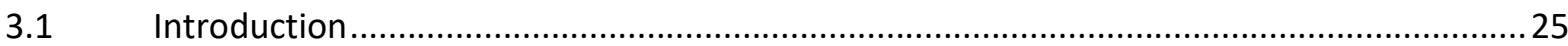

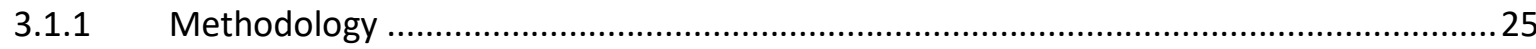

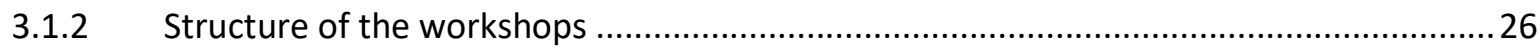

3.2 Theme A: What is the most appropriate overarching approach to measuring community

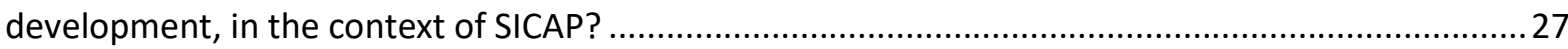

3.3 Theme B: Which indicators most effectively reflect changes in community development and the capacity of communities to effect change?

3.4 Theme $\mathrm{C}$ : In terms of the community group progression matrix, to what extent is progression the norm, and is progression along this matrix a true reflection of capacity building at a community level? 
3.5 Theme D: How can we improve the existing approach to data collection in order to more accurately reflect changes in community development in areas supported by SICAP? ......................38

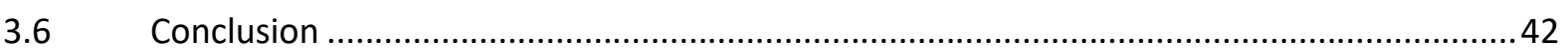

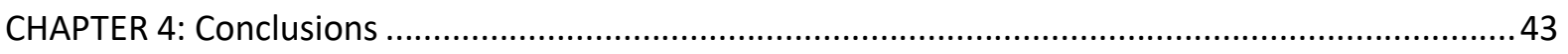

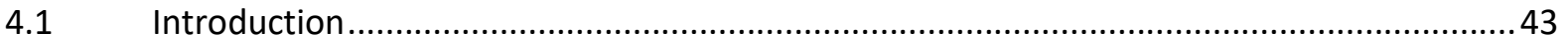

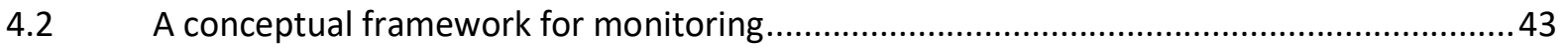

4.3 Challenges with measuring causal relationships using aggregate outcomes ......................45

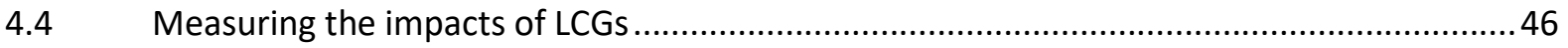

$4.5 \quad$ Limitations of the current data collection approach......................................................... 47

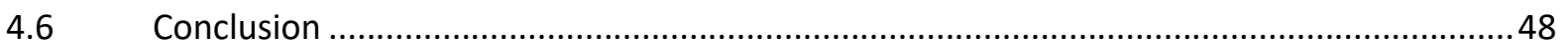

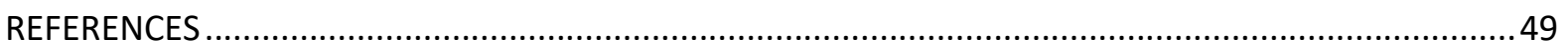

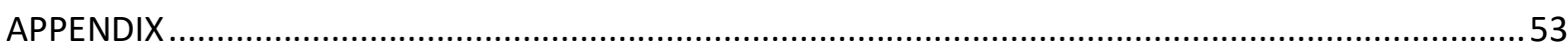

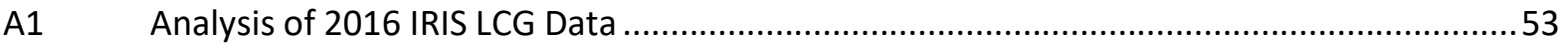

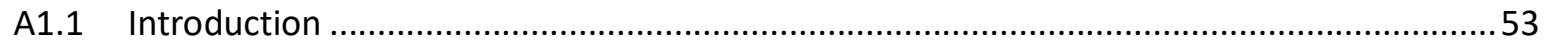

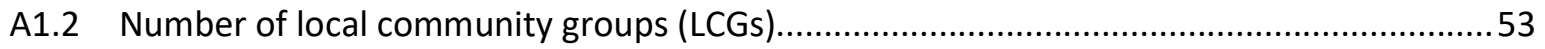

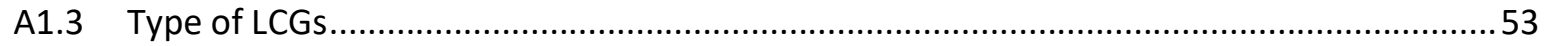

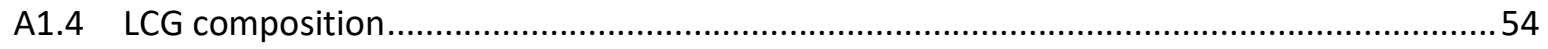

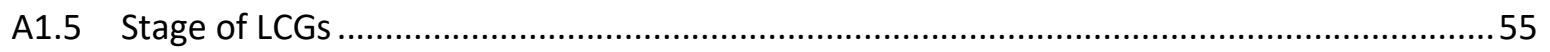

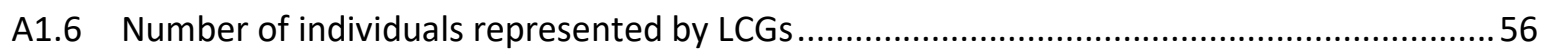

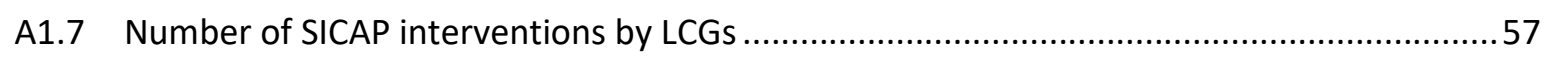

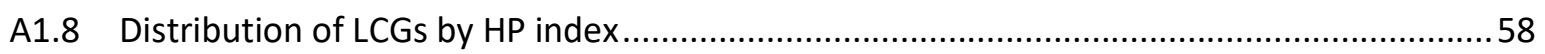

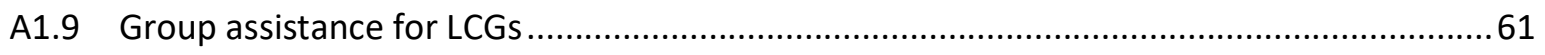

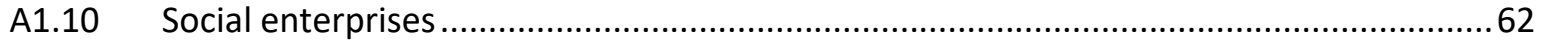

A2 Proposed indicators for measuring community development from consultation workshops.

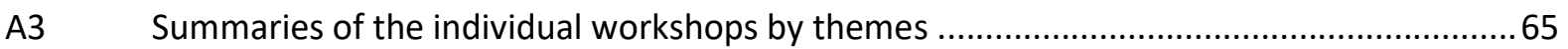

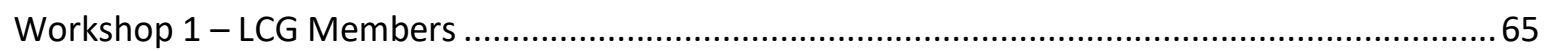

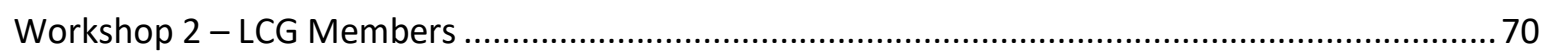

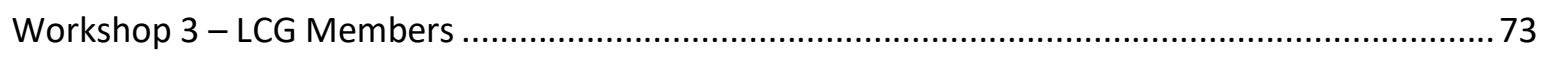

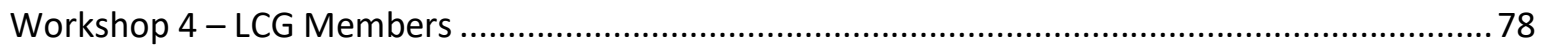

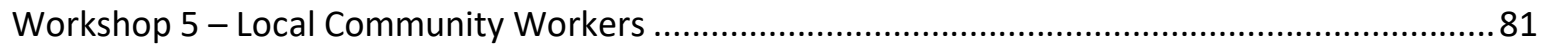

Workshop 6 - Local Community Workers and Stakeholders ....................................................... 84 


\section{LIST OF TABLES}

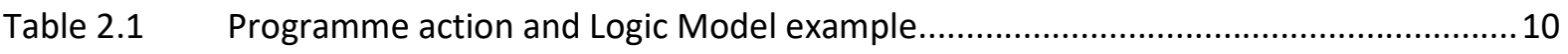

Table 2.2 Potential outcome and impact metrics at small-area level.............................................. 14

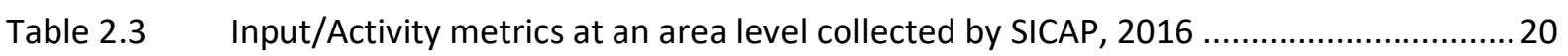

Table 2.4 Output and outcome metrics for LCGs at an area level collected by SICAP, 2016 .......20

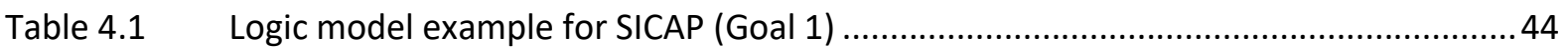

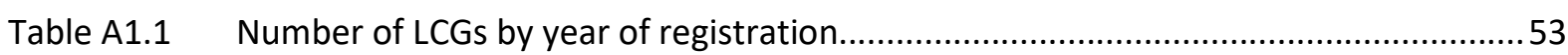

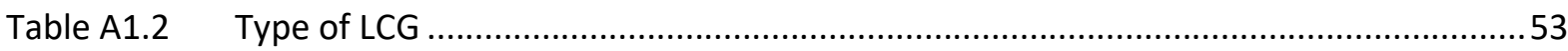

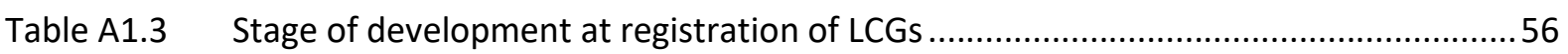

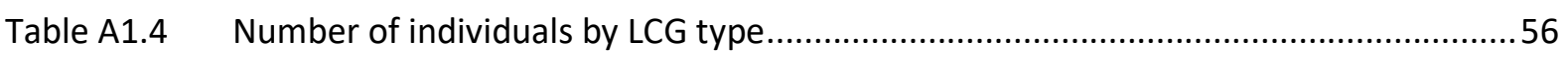

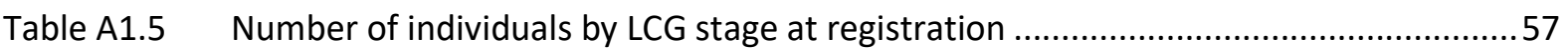

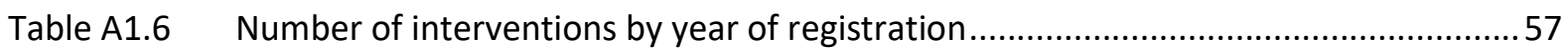

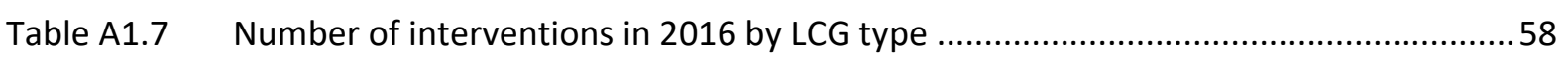

Table A1.8 Mumber of interventions by LCG stage of development ...........................................58

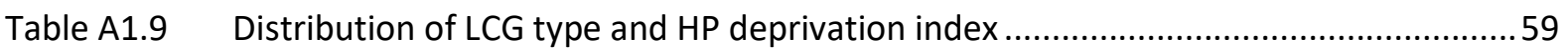

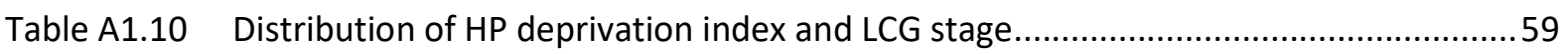

Table A1.11 Total number of individuals in an LCG by -HP Deprivation Index ....................................60

Table A1.12 Number of interventions per group in 2016 by HP Deprivation Index ........................60

Table A1.13 Level of involvement with LCG assisted to participate in local, regional and national

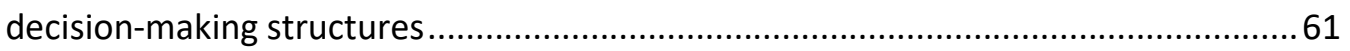

Table A1.14 Level of involvement with LCGs supported into a public participation network .........61

Table A1.15 Level of involvement with LCGs participating in annual planning and review processes

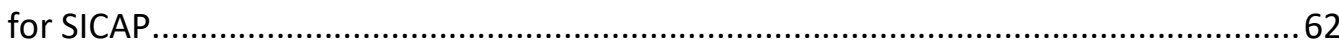

Table A1.16 LCGs assisting and establishing social enterprises.................................................62

\section{LIST OF FIGURES}

Figure 2.1 Circular overview of community development policy impact evaluation ..................... 7

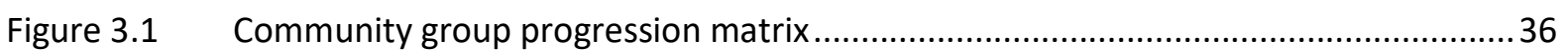

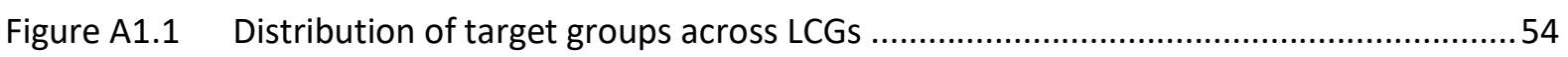

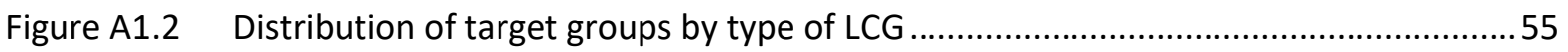

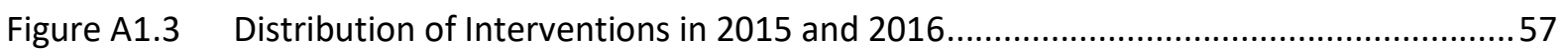

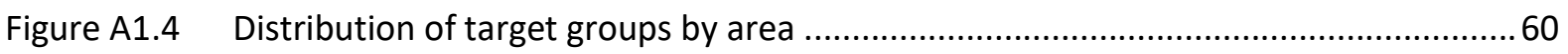





\section{ABBREVIATIONS}

$A B C D$

CD

CDW

CE

CLLD

COR

CSO

$\mathrm{CW}$

DHPLG

DRCD

DSP

ILDN

IRIS

KPI

LCDC

LCDP

LCG

LCW

LDC

LEAP

ONS

OR

PI

PPN

SICAP
Achieving Better Community Development (framework)

community development

community development work

Community Employment programme

community-led local development

community operational research

Central Statistics Office

Community Worker

Department of Housing, Planning and Local Government

Department of Rural and Community Development

Department of Social Protection

Irish Local Development Network

Integrated Reporting and Information System

key performance indicator

Local Community Development Committee

Local and Community Development Programme

local community group

local community worker

local development company

Learning, Evaluation and Planning

Office of National Statistics (UK)

operations research

programme implementer

public participation network

Social Inclusion and Community Activation Programme 



\section{EXECUTIVE SUMMARY}

\section{INTRODUCTION}

The Social Inclusion and Community Activation Programme (SICAP) represents a major component of Ireland's community development strategy, led by the Department of Rural and Community Development (DRCD). The vision of SICAP is to improve the opportunities and life chances of those who are marginalised in society, experiencing unemployment or living in poverty through community development approaches, targeted supports and interagency collaboration, where the values of equality and inclusion are promoted and human rights are respected. In 2016, total expenditure on SICAP amounted to approximately $€ 36$ million (Pobal, 2016a).

Using a mixed methodology, this report examines the extent to which community development programmes can or should be subject to evaluation, with a particular focus on SICAP. In doing so, the report draws on a rich body of information including desk-based research; consultation workshops with members of local community groups (LCGs), local community workers (LCWs) and other key policy stakeholders; and an analysis of administrative data held by Pobal - on the characteristics of LCGs that received direct support under SICAP. The findings in this report relate to the delivery of the SICAP 2015-2017 programme which ended in December 2017.

The aim of the study is to inform policy by shedding light on a number of issues including the following.

- Can community development be evaluated?

- What are the current metrics and methodologies suggested in the literature for evaluating community development interventions?

- What possible metrics can be used to evaluate community development interventions and how do these relate to the SICAP programme?

- How can a framework be developed that could potentially be used by SICAP for monitoring evaluation of its community development programme?

\section{MAIN FINDINGS}

- There are emerging attempts within policy circles to measure community development and well-being. Examples include the Community Tool Box, developed by the University of Kansas Work Group for Community Health and Development, and the Happy City Index, developed by What Works Centre for Wellbeing, UK. These approaches generally attempt to measure community- 
level well-being using very broad aggregates that are not linked to any particular policy intervention.

- No examples of formal evaluations to estimate the counterfactual impact of community development policies exist in either the academic or policy literature. There are a number of possible reasons for this, including: (i) the fact that outcomes of community development supports are often multidimensional and, as such, hard to measure and quantify; (ii) there are typically many state national agencies simultaneously implementing policies that impact well-being of local communities, making it impossible to disentangle the impacts of any specific national intervention on local outcomes such as poverty rates or educational attainment; (iii) local community organisations implementing initiatives directly targeting community welfare receive funding from multiple sources, making it difficult to isolate the impact of any particular funding streams on community-level outcomes; and (iv) it is often impossible to identify workable control groups not exposed to policy interventions in order to measure a counterfactual outcome.

- In the context of SICAP provision, formal measurement of the counterfactual is particularly problematic. SICAP funding on average represents a minority proportion of the funding for the majority of programme implementers (PIs), with many organisations in operation to pursue the same goals, which makes separating out causal impacts impossible. Darmody and Smyth (2018) analyse the financial reports for PIs in 2015 to determine that approximately half of PIs received a fifth or less of their funding through SICAP and only one-tenth received at least half of their funding through SICAP. It is also the case that local community groups funded under SICAP have a broad range of objectives and goals and do not tend to target narrowly defined measures of community wellbeing.

- Effective monitoring of community development initiatives is possible using additional information and approaches to more fully measure the impact of SICAP. Three specific suggestions for consideration are discussed within the report. First, the collection of broad metrics relevant to all groups funded under SICAP for use within a Logic Model framework is proposed. These broad metrics will largely focus on measures of the capacity of local groups to influence change at a community level. The Logic Model provides a framework for presenting the most feasible information by showing all inputs, activities/interventions, outputs, outcomes/impacts and the associated indicators. Second, in order to aid evaluation using a group-centred approach, a distance-travelled measurement tool for LCGs is proposed. This measuring tool would assist self-assessment by LCG members and LCWs for LCGs. The concept is broadly similar to that of an individual 'distance-travelled tool' that is currently being explored by Pobal for individuals, which often utilises a 0 to 10 scale for measurement across a number of relevant outcome measures. Finally, the systematic extrapolation of good practice from intermittent thematic reports would provide a unified view of changes that are occurring in the areas of community development as a consequence of SICAP. These reports 
can focus on specific impacts of funding on particular target groups, such as lone parents, the disabled or those facing homelessness. Such qualitative approaches allow for a more systematic and in-depth analysis of the impact of SICAP on community-level outcomes. The research provided detailed examples as to how these monitoring tools could be operationalised within the context of SICAP.

- Challenges associated with bottom-up approaches to the evaluation of SICAP are the comparability of evaluations across PIs and the incentive for PIs to amplify or inflate the value of their programme spending (subjectivity bias). To ensure an appropriate assessment, intermittent independent monitoring, preferably by a third party, can be used with a combination of assessment approaches, i.e. qualitative and quantitative analysis of key metrics (informed by the Logic Model approach) to obtain a balanced and objective view of progress.

- Other findings from the research show that there are limitations with the data currently collected by SICAP for LCGs. Some current metrics collected in the programme that measure inputs and ignore the intensity of interventions are likely to be uninformative in terms of monitoring programme impacts. Furthermore, the community group progression matrix, which has been used as a measure of programme impact at the LCG level, does not adequately measure the progression of the vast majority of LCGs. Findings from the consultation workshops and an analysis of administrative (IRIS) data held by Pobal highlighted that progression for LCGs is not always linear. We suggest that a distance-travelled tool for LCGs, and/or the use of narratives and milestones in quarterly reports, could be more appropriate for monitoring progress at this level. 



\section{CHAPTER 1}

\section{Introduction}

\subsection{RESEARCH AIMS AND APPROACH}

This report is part of a broader research programme designed to inform policy development regarding support for social inclusion programmes at community level. It adopts a mixed-methods approach, combining qualitative and quantitative analysis, to examine the extent to which community development programmes can or should be subject to evaluation, with a particular focus on the Social Inclusion and Community Activation Programme (SICAP). In doing so, the report draws on a rich body of information - including desk-based research; consultation workshops with members of local community groups (LCGs), local community workers (LCWs) and other key policy stakeholders; and an analysis of administrative (IRIS) data held by Pobal - on the characteristics of community groups that received direct support under SICAP. ${ }^{1}$ The work carried out in this report was funded by Department of Rural and Community Development (DRCD) and managed in conjunction with Pobal as part of the Research Programme on Community Development and Social Inclusion. The aim of the research programme is to create, improve and enhance knowledge on community development and social exclusion.

Previous research by the Economic and Social Research Institute has analysed the extent to which SICAP clients experience potential barriers to economic and social inclusion (McGuinness et al., 2018), an assessment of the goals and governance of SICAP (Darmody and Smyth, 2018) and an in-depth analysis of the training provided to programme beneficiaries (McGuinness et al., 2016). The approach utilised in this report sought to integrate insights from different data sources and relate these to the central aim of the research. The research is based on the SICAP 2015-2017 programme and most of the data used for analysis relate to 2016, which represented the most up-to-date information at the time of writing. A call for tenders, which contained an outline of the broad SICAP goals and governance of the new programme, was issued in August 2017. The new SICAP 2018-2022 programme has two goals which focus on community supports and individual supports respectively. As outlined by Darmody and Smyth (2018), the new framework introduces greater flexibility concerning target groups and the resource allocation across goals, thereby enhancing the capacity of SICAP to respond to local needs. Furthermore, LCDCs now have local-level input in setting targets and in selecting an additional target group over and above those specified in the programme guidelines. The new framework reduces the numbers of individuals 
and local community groups specified under the key performance indicators, and removes the headline indicators across a range of areas. ${ }^{2}$

The research questions to be addressed in the report include the following.

- Can community development be evaluated?

- What are the current metrics and methodologies suggested in the literature for evaluating community development interventions?

- What possible metrics can be used to evaluate community development interventions and how do these relate to the SICAP programme?

- How can a framework be developed that could potentially be used by SICAP to monitor evaluation of its community development programme?

The remainder of this chapter highlights the main goals of SICAP in Ireland.

\subsection{THE SICAP PROGRAMME}

The aim of SICAP is to reduce poverty and promote social inclusion and equality through local, regional and national engagement and collaboration. The vision of SICAP is to improve the opportunities and life chances of those who are marginalised in society, experiencing unemployment or living in poverty through community development approaches, targeted supports and interagency collaboration, where the values of equality and inclusion are promoted and human rights are respected.

Pobal (2018) has defined community development as 'a developmental activity comprised of both a task and a process. The task is social change to achieve equality, social justice and human rights, and the process is the application of principles of participation, empowerment and collective decision making in a structured and co-ordinated way.'

The programme is funded and overseen by the Department of Rural and Community Development with co-funding from the European Social Fund (ESF) under the Youth Employment Initiative. ${ }^{3}$ In 2016, total expenditure on SICAP amounted to approximately $€ 36$ million (Pobal, 2016b). Given the level of expenditure, there is scope to consider project evaluation. SICAP commenced on 1 April 2015 and in 2016, it had supported 3,056 LCGs and 47,511 individuals on a one-to-one basis. Following a tendering process covering 51 local areas or lots covering the whole area of Ireland, 45 programme implementers (PIs) were tasked

Other examples of changes implemented under SICAP 2018-2022 that were in planning at the time of the report preparation include changes to the community development matrix, addition of duration/intensity measurements of interventions with LCGs, and employing a survey of LCGs and LCG support plans.

3 Until July 2017 the programme was overseen by the Department of Housing, Planning, Community and Local Government. 
with delivering the programme according to nationally specified requirements. The work of the PIs is overseen by Local Community Development Committees (LCDCs) at local level, with Pobal taking a national oversight role regarding programme and operational requirements on behalf of the Department of Rural and Community Development.

The three core goals of SICAP are as follows (Pobal, 2016a, p. 5).

1. Strengthening local communities: Support and resource disadvantaged communities and marginalised target groups to engage with relevant local and national stakeholders in identifying and addressing social exclusion and equality issues.

2. Promoting lifelong learning: Support individuals and marginalised target groups experiencing educational disadvantage so they can participate fully in, engage with and progress through lifelong learning opportunities via community development approaches.

3. Helping people become more job ready: Engage with marginalised target groups/individuals and residents of disadvantaged communities who are unemployed but who do not fall within mainstream employment service provision, or who are referred to SICAP, to move them closer to the labour market and improve work readiness, and support them in accessing employment and self-employment and creating social enterprise opportunities.

SICAP interventions are directed at both individuals and groups. Some of the programmes provided by SICAP are: Business programmes; Job-Seeking and Job Preparation; Personal Development; Care and Health; Parenting; IT; Kickstart Preemployment; Enterprise; English; Driving; Construction and Trades; Food; Art, Craft and Design; Self-Employment; English for Speakers of Other Languages; Hospitality and Caring; Steps Pre-employment; Sports, Leisure and Tourism; Safe-Pass; Security; Start Your Own Business; Bookkeeping; First Aid; Manual Handling; Health and Safety; Community Capacity; Hair and Beauty; Business Planning; Cooking; and Languages. Individuals from a number of target groups, including individuals who are living in disadvantaged areas, are eligible to receive supports under the programme (Pobal, 2016a). Specific target groups are: children and families in disadvantaged areas; lone parents; NEETs (young people aged 15-24 years who are not in employment, education or training); new communities (including refugees/asylum seekers); people living in disadvantaged communities; people with disabilities; Roma; the unemployed (including those not on the Live Register); Travellers; low-income workers/households; and young unemployed people living in disadvantaged areas.

Furthermore, SICAP is underpinned by three horizontal themes relating to the core principles that cut across and have relevance to all areas of programme implementers' work. These are as follows (Pobal, 2016a, p. 6). 
1. Equality: Promoting an equality framework, with a particular focus on gender equality and anti-discrimination practices.

2. Community development methodologies: Applying community development approaches to achieve the participation of disadvantaged and marginalised communities in the wider local development context.

3. Collaborative approaches: Developing collaborative approaches with local (through the LCDCs) and national stakeholders to improve how mainstream policies and programmes are delivered so that they have a more positive impact on the socially excluded.

LCGs primarily benefit from supports provided under Goal 1, although a number of LCGs are also supported under Goal 3 where activities involve the development of social enterprises. Goal 1 sets as an objective the need to support and promote the community engagement of disadvantaged communities and individuals across the life-cycle. Therefore, it is concerned with the principles of participation, empowerment, capacity-building, collective action and decision-making in a structured way. As a consequence of engaging with LCGs representing and/or comprising the programme target groups, more active participation by individuals from these target groups is expected across the other SICAP goals.

LCGs are groups operating out of community work principles and processes focusing on the needs of SICAP target groups and/or those living in disadvantaged areas. Examples of LCGs include sports groups, knitting groups and active retirement groups. LCGs are categorised as issue-based, area-based or both. Issuebased groups focus on a particular target group or need (e.g. lone parents' group, those with disabilities) while area-based groups focus on the specific needs of a set area (e.g. residents' association or community council). Data are collected by the Integrated Reporting and Information System (IRIS), an administrative data capture system used by SICAP to record information on an LCG once it registers with SICAP. A list of metrics currently collected by SICAP is given in Table 2.4. Provision of these data is a mandatory requirement of PIs receiving funding under the SICAP programme. In 2016, 3,076 LCGs were assisted under SICAP and most of these groups were both area- and issue-based (64 per cent). LCGS that are predominantly area-based or issue-based constituted 17 per cent and 19 per cent respectively of the overall number of LCGs. ${ }^{4}$

The SICAP requirements (Pobal, 2016a, p. 21) state that supported LCGs should be all of the following:

- focused on and inclusive of at least one of the target groups of the programme;

- committed to the achievement of social inclusion and equality;

$4 \quad$ Authors' own calculation using IRIS 2016 data. 
- composed of the target group and, as appropriate, those working in solidarity with the target group;

- engaged in collective analysis and action;

- committed to the empowerment of the target group.

\subsection{OUTLINE OF THE REPORT}

This chapter has outlined the aim and approach taken to conducting the current study. The remainder of the report takes the following format. Chapter 2 summarises the desk-based component of the analysis, which examines the national and international literature related to measuring and evaluating community development programmes. Chapter 3 summarises the qualitative research conducted, focusing on the feedback from the consultative workshops, and Chapter 4 outlines conclusions. The appendix includes our analysis of the IRIS data for LCGs assisted by Pobal in 2016, plus detailed lists of all the proposed indicators for measuring community development and summaries from the individual workshops. 
6 | Valuing Community Development through SICAP 2015-2017 


\section{CHAPTER 2}

\section{Measuring community development}

\subsection{INTRODUCTION}

This chapter aims to summarise the international and national literature relating to the measurement and evaluation of community development programmes, examine proposed metrics that capture various aspects of community-level wellbeing, and summarise the data currently collected by Pobal under the SICAP programme.

In Figure 2.1, we have constructed a high-level summary of our overall findings. Within the academic and policy literature, there exist a number of theoretical frameworks (the Logic Model, Four Pillar Approach, ABCD model, LEAP framework, etc.) that provide suggestions on how progress in the community development sphere can be measured. Each of these theories generally involves a clear statement on programme objectives, which are linked explicitly to inputs, processes and outcome variables that the policy should be influencing.

\section{FIGURE 2.1 CIRCULAR OVERVIEW OF COMMUNITY DEVELOPMENT POLICY IMPACT EVALUATION}

3. Measures of Community Well-being

(e.g. Poverty rates, Community Health Indicators, Education Levels, Income Levels)
2. Programme Inputs \& Processes

(Linked to specific outputs that the policy should be influencing) 
Across the literature, we found no evidence of any systematic attempts to practically measure a counterfactual estimate of community-level outcomes. Our research highlighted many reasons why this might be the case. The key issue relates to the ability of researchers to demonstrate a causal link between a policy intervention and changes in broad measures of community well-being, shown by the break in the circular overview (Figure 2.1) between points (1) and (3).

The confounding factors contributing to the difficulties of trying to estimate the causal impact of policies targeting community well-being are as follows.

- Numerous national agencies simultaneously implement policies that will affect such broad outcomes, making it difficult to isolate the impacts of one particular policy.

- Local organisations targeting specific communities often receive funding from multiple sources, making it impossible to measure the impact of a particular funding stream even in instances where the community-level outcome measures are narrowly defined and identifiable.

- It may be more feasible to focus on narrower outcomes for the purpose of evaluating the impact of funding to community-level organisations. However, local community organisations tend to be highly heterogeneous in nature, with differing objectives, making it extremely difficult to identify a set of specific community-level outcome measures relevant to the activities of all funded groups. $^{5}$

- It is extremely difficult to identify control groups at a community level who have not been subject to any policy interventions against which to measure the counterfactual impact of an intervention.

Therefore, the expectation of measuring any causal influence of SICAP on broad community level outcomes, such as poverty rates or levels of educational attainment, was not felt to be practical due to the existence of various streams of funding targeting such outcomes and the overall complexity of the system. Furthermore, there is limited value in collecting such broad community-level aggregates for the purpose of a counterfactual evaluation.

Nevertheless, community development, similarly to all government-funded activities, requires monitoring and measurement. Effective monitoring of community development initiatives within the SICAP model is possible with the collection of broad metrics relevant to all local community groups for use within a Logic Model framework. The Logic Model links all inputs, activities/interventions, outputs, outcomes/impacts and the associated indicators and a suggested 
framework is proposed. Two further suggestions discussed at the workshops also seem to warrant further consideration: (i) a distance-travelled measurement tool for LCGs and (ii) intermittent national-level thematic qualitative studies.

\subsection{CONCEPTUAL APPROACHES TO MEASURING COMMUNITY DEVELOPMENT}

In the field of community development, it can be hard to know how deeply community development supports are impacting on participants and the wider community. Outcomes of community development supports are often hard to measure, because in essence they deal with social relationships and the complex functioning of groups and communities, which can be difficult to quantify (STARTTS, 2012, p. 49). Furthermore, sustainable change is linked to the wider impacts of a project on a community, and these can only be observed in the long term.

In order to measure the impact of community development supports, both qualitative and quantitative data are required. Quantitative or 'numeric' data quantify the measurable changes that have taken place as a result of the supports: for example, the pre- and post-programme assessment scales, which measure in numerical terms the change in participants' behaviour, well-being, values or capacity from before the project to its completion. Other examples of quantitative data include statistics from surveys or other relevant sources such as government records or programme files that can provide data on changes that have occurred at both an individual and a community level. Qualitative or 'non-numeric' data can generate rich explanations capturing the complexities, nuances and organic nature of community development projects. Examples include transcripts of interviews and focus group discussions, observation journals or project notes, open-ended questions from feedback forms or surveys, etc. Traditionally, qualitative data have been regarded as less rigorous or 'objective' than quantitative data. However, these indicators can be complementary and the importance of qualitative analysis for a field like community development is now widely recognised (STARTTS, 2012).

Indicators for developments in communities can be measured in two ways: using objective outcome measures such as population change and using subjective measures such as the residents' perceptions of change. Furthermore, a hybrid indicator such as an index can be used to quantify qualitative data. The aim of SICAP is to reduce poverty and promote social inclusion and equality through local, regional and national engagement and collaboration.

A number of conceptual approaches have been suggested for an overall framework to guide decisions around the particular metrics to be collected in any assessment of community development. Examples include the Logic Model, the four-pillar 
approach, the ABCD model and the LEAP framework, which we outline individually below.

\subsubsection{Logic Model}

A Logic Model is a tool that can be used by funders, managers and evaluators of programmes to evaluate the effectiveness of a community development programme, providing a simple framework under which metrics related to community development can be captured (Milstein and Chapel, 2011). This model has proved to be a successful tool for programme planning as well as implementation and performance management in numerous fields, including primary care (Frechtling, 2007).

While there are many ways in which Logic Models can be depicted, in the simplest form, four components of a programme are used: inputs (resources), activities, outputs and outcomes (Table 2.1). The Logic Model shows the logical relationships among the resources that are invested, the activities that take place, and the benefits or changes that result. The purpose of its construction is to attempt to assess the 'if-then' (causal) relationships between the elements of the programme. In Chapter 4 we create a Logic Model that can potentially be used by SICAP.

\begin{tabular}{|c|c|c|c|}
\hline Inputs & \multicolumn{1}{|c|}{ Activities } & Outputs & Outcomes/Impacts \\
\hline $\begin{array}{c}\text { What resources go } \\
\text { into a programme? }\end{array}$ & $\begin{array}{c}\text { What activities does the } \\
\text { programme undertake? }\end{array}$ & $\begin{array}{c}\text { What is produced through } \\
\text { those activities? }\end{array}$ & $\begin{array}{c}\text { What are the changes or benefits } \\
\text { that result from the programme? }\end{array}$ \\
\hline
\end{tabular}
Source: Milstein and Chapel, 2011.

\subsubsection{Four-pillar approach}

Pritchard and Kazimirski (2014) in association with New Philanthropy Capital (NPC) have published a 'four pillar approach' providing practical guidance on developing an impact measurement framework. The four pillars are: (i) mapping the theory of change; (ii) prioritising what is measured; (iii) choosing the level of evidence; and (iv) selecting the sources and tools. Moreover, they propose that the outcomes assessed should be ones that are directly influenced (rather than indirectly supported); are important or material to the mission; are not too costly to measure; and will produce credible data.

\subsection{3 $A B C D$ framework}

Perhaps the most detailed conceptual approach that has been developed to date is the Achieving Better Community Development $(A B C D)$ framework. This model is a general approach for planning, evaluating and learning from community development interventions devised by the Scottish Community Development Centre (Barr and Hashagen, 2000). The method aims to ensure that there is clarity about: 
(i) the aims of community engagement activity;

(ii) what activities will be undertaken;

(iii) how success will be measured.

The $A B C D$ framework sets out ten dimensions of community development in a structure of 'a healthy community', 'a strengthened community', 'quality of community life dimensions' and 'community empowerment dimensions'. This framework has been used as the basis for the Learning, Evaluation and Planning (LEAP) approach to identify three bases of evaluation (Barr and Dailly, 2007):

(i) expressed (from the viewpoint of the participants);

(ii) normative (relative to standards set down by authorised bodies and experts);

(iii) comparative (relative to conditions in other areas).

\subsubsection{LEAP Handbook}

Furthermore, the LEAP Handbook (Barr and Dailly, 2007) suggests a framework to identify outcome indicators, stressing that indicators need to be developed on a case-by-case basis to reflect the priorities of the stakeholders in an initiative, which relates to the following questions.

(i) How much has changed? (Quantity)

(ii) How beneficial has the change been? (Quality)

(iii) Who has benefited and who has not? (Equity)

(iv) What resources have been used? (Efficiency)

(v) How far have the planned outcomes been achieved? (Effectiveness)

The LEAP model advocates the development of meaningful indicators in collaboration with the stakeholders. This model suggests limiting the collection of data to answering the questions that are most relevant to understanding these issues (optimal ignorance), and not gathering data with more accuracy than is needed to understand the priority issues for evaluation (appropriate imprecision). They state that a useful indicator is measurable, precise or accurate, consistent and sensitive (changing proportionally in response to actual changes).

\subsubsection{Other approaches}

A less structured approach is suggested by Motherway (2006), who states that typical positive impacts of community development initiatives relate to more resources reaching excluded groups and communities; better facilities and services being provided; earlier, more effective interventions, especially in education; rising levels of participation and involvement; and, crucially, lower levels of measurable 
poverty in deprived communities. Emphasis is also placed on empowerment, increased levels of community spirit and mobilisation, and improved levels of community well-being generally. As stated above, in general there are limited quantitative elements in the evidence base and no systematic set of numerical indicators by which to measure impacts. Most discussions of impacts tend to focus on the dimensions of community activation and of personal benefits such as education, employment or access to benefits. There is little or no discussion of impacts in terms of political influence or structural change.

While it is not clear that any particular conceptual framework should guide the measurement of community development achieved under SICAP, each approach generally incorporates a clear statement on programme objectives, which are then linked explicitly to subsequent inputs and identified key outcome variables that the policy should be influencing. This is particularly important in the context of SICAP provision, where PIs (i.e. local development companies apart from the Dublin Inner City Co-op) draw funding from a range of sources, and SICAP funding mostly accounts for less than half of the total revenues (Darmody and Smyth, 2018).

\subsection{METRICS SUGGESTED IN THE LITERATURE FOR THE MEASUREMENT OF COMMUNITY DEVELOPMENT}

McGuinness et al.'s (2016) review of the international academic literature revealed little or no evidence of systematic attempts or methodologies associated with the measurement of community-level outcomes of education and employment supports similar to those operated under SICAP. It is highly likely that the paucity of such research again stems from a lack of reliable and centralised data collection on community-based activities and outcomes.

Within the general academic and policy literature, emphasis is placed on empowerment, increased levels of community spirit and mobilisation, and improved levels of community well-being generally. There are limited quantitative elements to the evidence base and no systematic set of numerical indicators by which to measure impacts. Furthermore, the exclusive impact and long-term consequences of a programme, e.g. reduced poverty rates, can be very difficult to ascertain since several other similar or dissimilar projects can potentially lead to the same impact. It must be borne in mind that disadvantaged individuals, families and communities take part in numerous programmes and are recipients of multiple services, many of which have differing time frames. Therefore, community impact may only be able to capture the cumulative effect of these measures rather than a single programme.

The Community Tool Box is a free online resource for community development which is used by professionals and local community groups (LCGs). It contains many proposed metrics that capture various aspects of community-level well- 
being. ${ }^{6}$ These are listed in Table 2.2 alongside potential sources to obtain these metrics in an Irish context. ${ }^{7}$ While some of the sources may not currently be publicly available at the small-area level, they do exist at a broader area level such as county or electoral district, and thus Table 2.2 in some cases illustrates metrics that can potentially be collected in the future and the associated source.

6 The Community Tool Box is a public service of the University of Kansas and developed by the KU Work Group for Community Health and Development and partners nationally and internationally (http://ctb.ku.edu/en).

7 A sample is included in Table 2.2; other objective indicators used in the community development and social impact literature include health and health utilisation, crime, residential mobility, social segregation, etc. 
Number of community activist and citizen advocacy groups and organisations

Number of single-parent families, and of children living with caregivers other than their parents

Diversity of the population - number/size of various ethnic \& racial groups, number of children under 18; and population trends - how these have changed over time

Census, CSO Percentage of residents who own their own homes (tenure status)

Census, CSO

10 Average commute to work of local residents

11 Percentage of people in poverty and/or with high deprivation levels

Census, CSO

12 Mean and median income

Census, CSO, HP Index ${ }^{9}$

Census, CSO

13 Median education level

Census, CSO

Occupancy rate for business and industrial buildings, and rental cost per square metre for such space

DHPLG $^{10}$

Total commercial real estate sales, and average sale prices for various kinds of commercial real estate

DHPLG

16 Average price of a single-family house

17 Details of households accessing local authority managed emergency accommodation

18 Default rate on mortgage and local business loans

19 Number of local businesses, as well as empty storefronts or offices

G/Daft/PPR ${ }^{11}$

\section{DHPLG/Daft/PP
DRCD}

Central Bank

Census of Industrial Production

Number of new businesses starting annually, and the number of business failures or bankruptcies each year

21 Percentage of local businesses and industries that are locally owned

22 Number of services firms

23 Unemployment rate

24 People entering the workforce

25 People discontinuing social welfare payments

26 Local revenue from taxes and fees

27 Number of new commercial buildings being constructed
Census of Industrial Production

Census of Industrial Production

Annual Services Inquiry DSP $^{12} /$ Census, CSO DSP

DSP

Revenue

Land Registry

Community-level impacts might be assessed by monitoring changes in the aggregate level of such metrics following the completion or introduction of a

Some of the metrics may not be available from the respective bodies and may have to be sourced locally. The Haase Pratschke (HP) Deprivation Index for Small Areas provides a method of measuring the relative affluence or disadvantage of an area using data compiled from various censuses, and is a key determinant of the amount of funding allocated to particular geographical areas under SICAP. Based on earlier deprivation indices for Ireland, as well as analyses from other countries, three dimensions of affluence/disadvantage are identified: demographic profile, social class composition and labour market situation.

10 Department of Housing, Planning and Local Government.

11 Property Price Register.

12 Department of Social Protection. 
programme. Purdon et al. (2001) outline a number of underlying principles that should be reflected in any primary survey approach to measuring change in community development. They emphasise that asking the question 'What has the impact of a programme been?' means addressing the 'counterfactual', i.e. 'What would the situation be if the programme hadn't existed?' Of course, quantification of this is extremely challenging.

Purdon et al. (2001) highlight the important decision of who are the 'subjects' of the evaluation. They suggest that the relevant actors can be considered in three main groups: (i) primary subjects (the individuals to whom the policy or programme is specifically targeted or who are directly affected by the policy or programme; for example, participants and non-participants); (ii) secondary subjects (the individuals who may have a key role in making the policy or programme work but are not integrally involved in the development or delivery of the policy or programme; for example, employers); (iii) actors involved in delivery (one of the key groups usually studied in evaluations is those involved in the delivery of new policies or programmes; for example, policy-makers or staff involved directly in delivery). Some methods of data collection are more costly than others in terms of time, people and money, depending on the scale of the project and the research questions to be addressed.

Other suggestions in this area come from the What Works Network, a UK government-led initiative to enable commissioners of public services to access independent, high-quality evidence syntheses across a broad range of social policy areas. It is made up of seven independent What Works Centres and two affiliate members. The centres aim to focus on understanding, improving and creating demand for the use of evidence in decision-making, focusing on key policy areas including:

- local economic growth;

- well-being;

- crime reduction;

- early intervention;

- poverty;

- public sector reform.

The What Works Centre for Local Economic Growth was established in October 2013 and is funded by the UK government. The centre aims to significantly improve the use of evidence in the design of policies for local economic growth and employment. Its approach includes evidence reviews, capacity-building and demonstration projects. 
The What Works Centre for Wellbeing has 17 founding partners including Public Health England, the Economic and Social Research Council, government departments, the Office for National Statistics and the Local Government Association. It was launched in October 2014 with the aim of developing a strong and credible evidence base to support these organisations to concentrate efforts on interventions that will have the biggest impact. The centre has commissioned a research synthesis of what works, and secondary data analysis, initially in three areas: employment and learning, community well-being, and culture and sport. Its research also focuses on measuring, analysing data, definitions, and identifying areas for further research on well-being.

Well-being is a subjective individual-level indicator that could potentially be collected with changes monitored at the aggregate level following the completion or introduction of a programme. The UK Office of National Statistics (ONS) recommends that if there is space/time for only one question relating to wellbeing, a life satisfaction question be used:

- Overall, how satisfied are you with your life nowadays?

If there is additional space/time, it recommends the Warwick Edinburgh Mental Wellbeing Scale, covering four personal well-being questions and four perspectives on an 11-point scale where 0 means 'not at all' and 10 means 'completely'.

- How satisfied are you with your life nowadays? (Evaluative perspective)

- To what extent do you feel that the things you do in your life are worthwhile? (Eudaimonic perspective)

- How happy did you feel yesterday? (Positive experience perspective)

- How anxious did you feel yesterday? (Negative experience perspective)

Online surveys and polls can be used to collect data on participants' satisfaction and to inform programme development (Ollerton and Black, 2017). Online surveys with users or engaged participants can be a quick and easy way to collect data on people who have already been reached and/or engaged with in some way. These post-event surveys and interviews can be sent to registered users via email, or posted on a website or social media page. Survey Monkey can also be used to create surveys with links that can be posted on Twitter or embedded in other social media networks.

Happy City developed an online survey measurement tool, the Happiness Pulse, consisting of 20 questions in order to gather valuable data on the well-being of people in Bristol from April to July 2016. ${ }^{13}$ The Happiness Pulse was designed to be

13 Please see http://www.happycity.org.uk/wp-content/uploads/2016/10/Happy-City-Wellbeing-Measurement-AGuide-to-Quantitative-Data-collection.pdf, p. 30. 
a well-being health-check that could be taken just once, several times over the course of a few months or as a before-and-after impact evaluation of projects and interventions. Because the Happiness Pulse includes national measures of wellbeing (ONS life satisfaction questions and Short Warwick-Edinburgh Mental Wellbeing Scale (SWEMWBS)), the composite measures can be compared to other national datasets. Gathering representative nationwide or city-wide data is very difficult without population contact details, so they experimented with a partnership strategy, working with umbrella organisations in key sectors across Bristol (health, voluntary, culture, business, environment) to promote the Happiness Pulse to their members and staff. Each organisation was given a unique URL and code allowing them to collect well-being data specifically within their organisation. After the trial, Happy City provided them with the Happiness Pulse data for their organisation, a mutual benefit of well-being data collection.

The What Works Centre for Wellbeing has partnered with Happy City, which has three pioneering measurement and policy tools, as follows.

- Happiness Pulse ${ }^{14}$ is an interactive survey that aims to measure well-being across three domains: mental/emotional well-being, behavioural well-being, and social well-being in urban communities.

- Happy City Index ${ }^{15}$ is an annual progress report on the conditions for well-being at a city or local authority level, which aims to help decision-makers understand and assess the city determinants of well-being.

- WellWorth Policy Tool ${ }^{16}$ is an evaluation tool currently in an extended piloting phase, which aims to assess the impact and cost benefits of well-being interventions across key policy areas.

\subsection{DATA CURRENTLY COLLECTED BY SICAP THAT COULD POTENTIALLY BE INCORPORATED INTO A MEASUREMENT APPROACH}

We next provide an overview of the data that are currently collected by SICAP, examine the limitations and assess the extent to which various measures can be captured and improved under any evaluation/monitoring approach guided by an overall conceptual framework. Bamber et al. (2010) state that programme design is most likely to be robust and effective when it is underpinned by a clear theoretical framework, which makes explicit the expectations as to why providing a specific input should lead to a change in a specific outcome.

SICAP is underpinned by community development principles, so activities under all goals (1,2 and 3 ) are designed to promote social inclusion and enhance community 
outcomes. At present, detailed information is collected on the individuals who avail of education and employment supports (goals 2 and 3). However, their outcomes are measured at individual level only; for example, in terms of progression to education, training and employment. There is considerable potential to adopt the kinds of metrics discussed in the previous section in looking at the potential impact of availing of supports on individual well-being more broadly as well as the impact of individual participation on the community as a whole. In the remainder of this section, we concentrate on information collected in relation to Goal 1, which focuses on working with local community groups, while recognising that this represents a narrow way of assessing community development measures.

Important information is currently collected in terms of the number of key community development interventions that take place under SICAP in any given year. For instance, SICAP commenced on 1 April 2015 and in 2016, SICAP had supported 3,056 LCGs and 47,511 individuals on a one-to-one basis.

Support interventions are recorded when the PI engages with an LCG and provides support under one of the following support categories.

- G1.1 To support and promote the community engagement of disadvantaged target groups across the life-cycle.

- G1.2 To support the development of LCGs which promote equality and social inclusion in a local, regional or national context.

- G1.3 To support disadvantaged communities and individuals to enhance their participation in local, regional and national decision-making structures.

- G1.4 To develop and facilitate strategic collaborative frameworks and networks as part of a dialogue for developing solutions to social exclusion.

Data are captured in a way that allows for the separation of community interventions by support category. However, there are limitations with the data that are currently collected by SICAP for LCGs, partly due to the types of questions asked and due to the fact that the data are collected at the point of registration. According to the SICAP programme requirements, a minimum of two support interventions must be provided to an LCG within a calendar year in order for the interventions to be recorded as part of the LCG's headline indicators. With regard to G1.1, most LCGs in 2016 (63 per cent) worked with people living in disadvantaged communities, while almost half (44 per cent) worked with children and families living in disadvantaged areas, over a quarter ( 23 per cent) worked with the unemployed, including those not on the Live Register, and a similar proportion (24 per cent) worked with people with disabilities. The target groups with the lowest levels of engagement by LCGs in 2016 were Travellers (8 per cent) and Roma 
(1 per cent), but their engagement levels are higher relative to their representation in the overall population. ${ }^{17}$

Again, metrics are collected in terms of the number of interventions targeted at the various stages of community group development. Objective G1.2 seeks to support the development of LCGs that promote equality and social inclusion in a local, regional or national context. In 2016, 28 per cent of LCGs received support interventions related to group formation and development (G1.2).

There is an emphasis on facilitating LCGs' progression along the community development matrix, which comprises four stages:

- Stage 1: Pre-development and group formation;

- Stage 2: Capacity-building and empowerment;

- Stage 3: Collective action;

- Stage 4: Strategic involvement in policy and decision-making processes at a local, regional and/or national level.

In 2016, 10 per cent of all LCGs recorded progression along the community development matrix. ${ }^{18}$ The majority of movements ( 47 per cent of those that moved) was from Stage 2 to Stage 3, with the next highest (32 per cent) moving from Stage 1 to Stage 2. The LCGs that progressed along the community development matrix on average received eight support interventions, compared to an average of four interventions for all LCGs supported under SICAP (Pobal, 2016a).

Support interventions totalling 1,854 related to participation in local, regional and national decision-making structures (G1.3). With regard to G1.4, 121 LCGs (4 per cent) were supported to put anti-discrimination and equality measures in place. Examples of activities supported under this goal include participation of LCGs in disability awareness days, Traveller cultural awareness training and workshops focusing on issues of inequality and discrimination.

\subsection{INPUT/ACTIVITY METRICS AT AN AREA LEVEL COLLECTED BY SICAP}

In addition to data on the number and nature of LCG interventions, a number of additional key metrics are captured annually in IRIS which can also potentially be incorporated in a community measurement approach (Tables 2.3 and 2.4).

\footnotetext{
Authors' calculation using IRIS 2015-2017 data.

Ongoing research on SICAP indicates that many PI staff are critical of this approach to framing the 'progress' of LCGs and suggest that it fails to capture the diversity of purpose among LCGs.
} 


\section{1}

Number of LCGs assisted under SICAP (KPI)

3,076

Total number of disadvantaged individuals (15 years and upwards) engaged

under SICAP on a one-to-one basis (KPI)
47,511

Source: Pobal (2016a).

TABLE 2.4 OUTPUT AND OUTCOME METRICS FOR LCGS AT AN AREA LEVEL COLLECTED BY SICAP, 2016

1 Proportion of LCGs assisted in their formation, development and progression

2 Proportion of LCGs that progressed using the structured progression path of development model

3 Proportion of LCGs assisted to leverage funding (and the amount of funding received)

4 Proportion of LCGs assisted to participate in local, regional and/or national decision-making

The level of LCG involvement in those structures was estimated on a three-point scale:

(i) somewhat involved

(ii) very involved

(iii) extremely involved

5 Proportion of LCGs supported into a public participation network (PPN)

The level of LCG involvement in those structures was estimated on a three-point scale:

(i) somewhat involved

(ii) very involved

(iii) extremely involved

6 Proportion of LCGs participating in annual planning and review processes for SICAP

The level of LCG involvement in those structures was estimated on a three-point scale:

(i) somewhat involved

(ii) very involved

(iii) extremely involved

7 Proportion of LCGs supported to put anti-discrimination and equality measures in place ${ }^{19}$

8 Proportion of LCGs supported to assist social enterprises

9 Proportion of LCGs that received SICAP funding to assist social enterprises

10 Proportion of LCGs that established new social enterprises

N

Source: Pobal, 2016.

\subsection{CAN METRICS CURRENTLY CAPTURED UNDER SICAP BE IMPROVED?}

It is clear that a large amount of information is currently collected by SICAP relating to the inputs, activities and outputs of funding to community groups. An obvious question related to the objectives of the current study is how these can be improved to allow better monitoring and evaluation of community-level

19 Examples of activities under this support in 2016 included: group leaders were supported to deliver Traveller cultural awareness training to the Local Traveller Accommodation Consultative Committee and senior officials in the housing unit of local authorities; delivering a workshop on mental health stigma; group members attended events to gain information about barriers and equality issues and learn how to overcome these. 
interventions. We summarise some of the main observations at this stage of the study which formed the basis of the discussions at the consultation workshops with LCWs, members of LCGs and other stakeholders.

\subsubsection{Number versus intensity}

The current metrics monitor the number of individuals and activities, but improvements could be made in order to capture the varying levels and intensity of programme activities and interactions. Intensity measures can relate to the resources allocated to interventions in terms of either time or cost (or both).

For example, in 2016, 34 per cent of LCGs were assisted to participate in local, regional and/or national decision-making structures. The level of involvement is captured on a three-point scale: (i) somewhat involved, (ii) very involved and (iii) extremely involved. However, it may also be helpful to capture the associated duration of meetings, the total number of individuals involved and/or the expenditure attached to this specific element of the SICAP goal.

\subsubsection{Balance between qualitative and quantitative outcomes}

Pobal currently collects outcomes relating to three horizontal themes - (i) equality, (ii) community development methodologies and (iii) collaborative approaches - in a qualitative way. In addition, work with other agencies and leveraging service is a core part of the PI's role but is not well captured using the current metrics. It may be possible to consider the application of basic standardised metrics to capture developments across these themes.

\subsubsection{Process and implementation monitoring}

A process evaluation or implementation assessment is a form of programme monitoring designed to determine whether the programme is delivered as intended to the targeted recipients (Rossi and Freeman, 1982). Purdon et al. (2001) make a distinction between measuring process and measuring impact, arguing that they are entirely different goals. This creates additional challenges for community development, where process dimensions are so important and yet so hard to evaluate. For example, Pobal could potentially collect information to examine:

- processes such as finding out about a service;

- whether all those eligible receive the programme; who does/does not participate, and why;

- finding out about a service delivery;

- whether service delivery is consistent with the programme's intention;

- identifying any variations in service delivery; 
- whether programme resources/programme delivery are consistent across all locations;

- looking at the programme's resources;

- whether costs per unit are reasonable;

- looking at participants' experiences of the programme;

- whether participants are satisfied with their interactions with staff delivering the programme, with the procedures, and with the services they receive.

\subsubsection{Cost considerations}

Finally, as outlined by McGuinness et al. (2016), the cost of additional data collection and qualitative assessment elements has to be weighed against the overall cost of the programme's delivery, which, in some cases, can be quite low. This suggests that it may not be sensible to collect all metrics for all interventions.

\subsection{CONCLUSION}

This chapter has examined the international and national literature relating to the conceptual approaches proposed for the measurement and evaluation of community development programmes. Furthermore, it has examined proposed metrics that capture various aspects of community development and well-being and reviewed the data currently collected by Pobal under the SICAP programme.

It can be extremely complex to understand exactly how deeply a community development approach is impacting on participants and the wider community. A number of conceptual approaches have been suggested to provide an overall framework to guide decisions around the particular metrics to be collected in any assessment of community development; examples include the Logic Model, fourpillar approach, ABCD model and LEAP framework. While it is not clear that any particular conceptual framework should guide the measurement of community development achieved under SICAP, each approach generally incorporates a clear statement on programme objectives, which are then linked explicitly to subsequent inputs and identified key outcome variables that the policy should be influencing.

Within the general academic and policy literature, emphasis is placed on empowerment, increased levels of community spirit and mobilisation, and improved levels of community well-being generally. There are limited quantitative elements to the evidence base and no systematic set of numerical indicators by which to measure impacts. Furthermore, the exclusive impact in terms of longterm consequences of a programme, e.g. reduced poverty rates, can be very difficult to ascertain since several other projects, similar or dissimilar in nature, can potentially lead to the same impact. 
It is evident that a large amount of information is currently collected by SICAP relating to the inputs, activities and outputs of funding to community groups. The current metrics monitor the number of individuals and activities, but improvements could be made in order to capture the varying levels and intensity of programme activities and interactions. Furthermore, in order to capture more fully the impact of community development projects, a balance between qualitative and quantitative outcomes is required. There needs to be a greater distinction between measuring process and measuring impact, as arguably they are entirely different goals. Finally, the cost of additional data collection and qualitative assessment elements has to be weighed against the overall cost of the programmes, which, in some cases, can be quite low. This suggests that it may not be sensible to collect all metrics for all interventions. 
24 | Valuing Community Development through SICAP 2015-2017 


\section{Qualitative research: feedback from consultative workshops}

\subsection{INTRODUCTION}

In October 2017, the ESRI organised a series of six consultation workshops. Stakeholders engaged very positively, with 129 people attending the sessions in total. In line with the community development literature, Midgley et al. (2017) highlight the need for communities to have a substantial input into how community problems are addressed, describing community operational research (COR) as not just applying operational research methods to community development: it is the 'meaningful engagement of communities which is most important'. Operations research (OR) is a problem-focused discipline in which the selection of methods is guided by the features of the particular problem and decision processes at hand, with flexibility to customise the blend of quantitative and qualitative approaches.

In addition, Midgley et al. (2017) stress the importance of the term 'enhanced OR', which suggests that it is crucial to supplement the traditional problem-solving 'conventional $\mathrm{OR}^{\prime}$ with engagement of communities and stakeholders. This is especially true given the research questions of our study. Furthermore, they stress that community members should be at the heart of the decision-making process and that it is not feasible to fully identify the problem of the community without consulting and engaging the community members. ${ }^{20}$ This study uses an integrated participatory approach alongside the desk-based research and the analysis of the IRIS data in order to explore the possibility of impact evaluation for community development projects such as SICAP.

\subsubsection{Methodology}

We organised a series of six consultation workshops involving members of local community groups (LCGs), local community workers (LCWs) and other key stakeholders, such as representatives from Community Work Ireland (CWI), the Irish Local Development Network (ILDN), the Irish National Organisation of the Unemployed (INOU), and Pavee Point, in order to capture their views across a

20 COR has been applied to many community projects across a variety of countries. René Victor Valqui Vidal (2009) discussed how COR was used to support a LEADER+ programme in Denmark. A series of workshops were carried out in order to identify and design projects to aid community development and decision-making processes that led to agreement of action plans. Wang et al. (2018) applied COR to a project in Wales which was focused on improving access to affordable fresh food in a disadvantaged community. They used qualitative comparative analysis in addition to soft systems methodology and strategic choice in order to develop solutions that gave the affected community members greatest involvement in the decision-making process. Fabusuyi (2018) discussed a community intervention focused on reducing crime in Pittsburgh, USA. A mix of qualitative and quantitative methods were used to help improve the availability of affordable housing, which could lead to improved quality of life and hence indirectly affect crime levels. McKenna et al. (2018) used a mixed-methods approach, conducting public workshops and applying OR methods such as energy modelling and multi-criteria decision analysis to help elicit individual preferences concerning an energy resource design project in rural Germany. 
range of themes. Specifically, we held four separate workshops for members of LCGs and two workshops for LCWs and other key stakeholders during the month of November 2017. In total 129 participants took part in these sessions. ${ }^{21}$ The workshops were organised across six lots, with each lot area chosen to reflect diversity in terms of geography, client base and the focus of PI activities.

The aim of the workshops was to explore key indicators of community development and community well-being, and to examine the feasibility of indicators emerging from the desk-based research in an Irish context and the extent to which the concept of community development could or should be measured. Furthermore, it was an opportunity for members of LCGs, LCWs and other key stakeholders to suggest metrics, and/or approaches, that could potentially be adopted for monitoring and evaluation purposes within (or potentially outside) IRIS.

\subsubsection{Structure of the workshops}

The workshops started with a short presentation of the project, including the goals, methodology and the results from the desk-based research. After this presentation, semi-structured round-table discussions revolving around different aspects of the study took place and were moderated by facilitators (chosen from among the participants and each assigned to a particular theme for the duration of the event). All workshop participants had the opportunity to express their views across the four main themes identified and listed below. At the end of the roundtable discussions the facilitators summarised the feedback from the participants in a presentation and the researchers/authors summarised the main findings of the workshop before concluding it.

Feedback was recorded by the use of flipcharts, which the facilitators took notes on and used when presenting feedback. In addition, the researchers took notes while the facilitator presented the feedback so as to gather any additional information that arose during the presentation. These notes and flipcharts were then analysed to capture the common themes that emerged from the discussions, which we discuss below. The themes for the workshops and related sub-sections of this chapter are organised into the following four main topics.

A. Approach: What is the most appropriate overarching approach to measuring community development, in the context of SICAP?

B. Indicators: Which measures most effectively reflect changes in community development and the capacity of communities to effect change?

21 Originally, we had proposed two workshops for LCWs and six workshops with LCG members. Two of the workshops with LCG members were cancelled due to insufficient numbers registered. Those who had registered for the two cancelled locations received copies of the presentation by email and were invited to make contact with the authors by phone or email, which the majority did. 
C. Progression: In terms of the community group progression matrix, to what extent is progression the norm and is progression along this matrix a true reflection of capacity-building at a community level?

D. Improve: How can we improve the existing approach to data collection in order to more accurately reflect changes in community development in areas supported by SICAP?

In addition to the consultative aspect of this research project, Darmody and Smyth (2018) simultaneously conducted another piece of research entitled The Goals and Governance of the Social Inclusion and Community Activation Programme (SICAP) 2015-2017: A Mixed Method Study. Although their study covered a wider range of research questions than the focus of this report, we were able to incorporate some aspects that directly related to impact evaluation for community development programmes such as SICAP. Specifically, we draw on issues emerging from interviews conducted by Darmody and Smyth (2018) with PI CEOs and workers involved in Goal 1 (strengthening local communities) related to the themes from the workshops. In this context, stakeholders mainly discussed metrics for SICAP 2015-2017. The interviews were conducted in early 2017 in ten case-study areas selected to capture variation in demographic profile, size of budget, region and perceptions of SICAP derived from a survey of PIs.

\subsection{THEME A: WHAT IS THE MOST APPROPRIATE OVERARCHING APPROACH TO MEASURING COMMUNITY DEVELOPMENT, IN THE CONTEXT OF SICAP?}

As emphasised both by previous research and by the lack of robust evaluations attempting to estimate the counterfactual impact in the community development space, it is extremely difficult to capture the impacts of interventions and expenditure that occur at the community level. Motherway (2006) summarises this difficulty by stating that 'there is no simple, universal, magical way to measure the outcomes and impacts of community development'. Nevertheless, the vast majority of members of LCGs and LCWs participating in the workshops stressed that community development, like other interventions, requires monitoring and measurement of the processes, outcomes and impacts achieved. There was certainly an overall acknowledgement of the complexity of this task, but participants communicated a strong willingness to realise methods that are appropriate both for the interests of marginalised communities and groups and for the needs of the state and other funders.

Community workers and LCG members emphasised that they currently strive to find ways to plan, measure and evaluate the impact of their community development work in order to point clearly to its impacts. Overall, it was conveyed in the workshops that there was a strong need for local flexibility in order to facilitate motivation and participation at the local level. It was felt that, due to the diverse needs of different localities and the heterogeneous nature of LCGs, a 'one- 
size-fits-all' approach to measuring community development would not be practical across all communities and target groups.

In terms of an overarching framework, there was a consensus in support of an approach similar to the Logic Model whereby processes and outcomes are specific to the supports and outcomes of SICAP (see Chapter 2 and Table 4.1, where we have attempted to develop a Logic Model using the SICAP framework). However, one key issue identified with this approach was the inability to directly attribute SICAP funding to any particular outcome, or impact, given the multiplicity of funding in the community development space. This issue is apparent in the existing data: for instance, in 2016, SICAP funding was found to represent a minority proportion of the funding for the majority of programme implementers (PIs), which makes separating out causal impacts impossible. Darmody and Smyth (2018) analyses the financial reports for PIs in 2015 to determine that approximately half of PIs received a fifth or less of their funding through SICAP and only one-tenth received at least half of their funding through SICAP.. On the other hand, community workers also reported this aspect as a key benefit of SICAP funding, suggesting that it enables PIs to more successfully obtain, and effectively use, other funding streams for the benefit of marginalised individuals and groups. However, due to the existence of such different streams of funding and the complexity of the system, the expectation of measuring any causal influence of SICAP on communitylevel outcomes was not felt to be practical.

The efficiency of measurement at a broad aggregate level, using methods similar to the Community Toolbox, which includes measures such as political participation and percentage of people in poverty and/or experiencing high levels of deprivation (see Chapter 2 and Table 2.2), was questioned and seen as less accurate than measurement at the community level. Participants perceived that census information, especially at small-area level, could potentially be used to capture the cumulative impacts of all activities, carried out by all actors, in the area, but only if there was an overarching multi-agency approach: for example, a unified framework across all agencies whereby they would work towards a common set of clearly defined goals informed by a common understanding of community development. Nevertheless, respondents generally felt that the collection of broad measures of community development was of somewhat limited value; some particular difficulties were expressed around issues such as measuring longer term changes in deprivation levels, failure to capture potential spill-over effects ${ }^{22}$ and difficulties establishing baseline data as a benchmark across locations.

LCWs suggested that community-led local development (CLLD) ought to be the grounding ethos that is fully embedded and embraced by SICAP. Under CLLD, local people take the reins and form a local partnership that designs and implements an 
integrated development strategy (European Commission, 2014). ${ }^{23}$ The strategy is planned to build on the community's social, environmental and economic strengths or 'assets' rather than focus on compensating for its difficulties. This need for structured planning at a community level was echoed by LCG members, who stressed the importance of having a community plan outlining high-level goals, community objectives and actions. This method was described by a participant informally as a 'community development tape measure' that could be referred to by LCGs, community workers and funders in order to aid measurement of outcomes.

A further related recommendation, with particular reference to LCGs, was to build a clear statement on 'what you want to change'. This was viewed as an important initial step that was sometimes neglected, which would facilitate increased structure in designing strategies, processes and measurements of outcomes at the local level. Various LCGs understandably need guidance and assistance to clarify their core focus, especially at the early stages of development. However, it was stated during workshops with LCWs that the expertise, experience and qualifications of community workers and partnerships ensured they were well placed in terms of guiding and assisting LCGs and outlining the collective determinants of community-level well-being within their geographical areas.

Furthermore, the LCWs suggested that the horizontal themes underpinning SICAP, relate to the core principles of the promotion of equality, community development methodologies and collaborative approaches, should play a greater role in the programme. ${ }^{24}$ It is likely that the impacts of planning approaches that are specifically tailored to the needs and objectives of local communities, such as CLLD, could not be easily captured in a standardised set of metrics and would instead require measurement using qualitative tools.

As discussed in Section 3.1, an alternative study by Darmody and Smyth (2018) included interviews with PIs, CEOs and workers involved in Goal 1 activities of SICAP 2015-2017. This report incorporates new analysis from that study. A number of staff mentioned the need for qualitative measures to explicitly capture the societal value of the work carried out, while recognising the challenges involved in

23 CLLD was the core focus of the predecessors to the SICAP programme (Local and Community Development Programme (LCDP) and Local Development Social Inclusion Programme (LDSIP)), whereby local development plans were developed in partnership with communities and relevant agencies.

24 The importance and relevance of the horizontal themes underpinning SICAP, which relate to the core principles of the promotion of equality, community development methodologies and collaborative approaches that cut across and have relevance to all areas of PIs' work, were stressed (Pobal, 2016a). For more information, please see https://www.pobal.ie/programmes/social-inclusion-and-community-activation-programme-sicap-2018-2022/. Another example was the All Ireland Standards for Community Work, which are framed around five core community development values: collectivity; community empowerment; social justice and sustainable development; human rights, equality and anti-discrimination; participation (All Ireland Endorsement Body, 2011). For more information please see http://communityworkendorsement.com/wp-content/uploads/2011/01/All-Ireland-Standards-forCommunity-Work.pdf 
developing such measures:

We just capture it ... you know when we write under ... we had a training and we did that or whatever. But, I mean, as regards to whether that's having an impact or how that group is having an impact and what that group is doing. And then the health benefits and the social benefits and the example that these people are. And people are engaged in a civic manner socially, all these have huge benefits. It's an example to their kids and the kids are going to school and they see you have to get back to society. I mean I don't know how you capture that. I mean it's a daunting task. I mean even for ourselves like we're trying to look at social investment tools or social monitoring tool, you know, monitoring our social impact. What's the societal value? How do we best do that? I mean there's loads of different tools out there as I'm sure you know far more than me ... And we [would] really like to have the time just to basically to get our heads around it but like we're ... constantly chasing the tail for the next report.

The societal value of it and somehow or other I think that needs to be factored back into it ... because I think that's what makes the type of work that we do a bit different ... And it sort of fills a space that's not being filled ... So I think something like that needs to be looked at as well as in terms of what's being measured and not.

During the workshops, resources and cost considerations were also discussed in regard to the overarching approach to measuring community development, in the context of SICAP. Community workers and LCG members emphasised the need for the overall cost of evaluation to be reasonable and balanced against the overall investment in a community development programme. Again, the importance of qualitative measures such as case studies was highlighted, along with the associated resource and time requirements and additional administration burden placed on staff in order to document the information as required.

In line with this, it is important to assess the relative cost of any additional data collection and qualitative assessment with the overall cost of the programme, which in some cases may imply that it may not be sensible to collect all metrics, for all interventions, at every time point (McGuinness et al., 2016). However, LCWs suggested that intermittent national-level thematic qualitative studies could be used to provide more detailed assessments of community-level development. For example, Pls could be asked to demonstrate community-level developments in specific thematic areas using local case studies to more accurately reflect the changes at a community level. ${ }^{25}$

25 Thematic reviews are currently being considered by Pobal. 


\subsection{THEME B: WHICH INDICATORS MOST EFFECTIVELY REFLECT CHANGES IN COMMUNITY DEVELOPMENT AND THE CAPACITY OF COMMUNITIES TO EFFECT CHANGE?}

Participants stressed that any measurement framework at the LCG level must represent the differing nature of LCGs and the levels of intensity required to build and maintain each group. Therefore, in terms of measuring SICAP interventions, the importance of individual measures of the type, duration and frequency of interventions was emphasised. It was highlighted that both the quantity and quality of the support interventions should be valued. In terms of quantifying outputs arising from interventions, the measurement of networks built and collaboration with other groups was seen as important in order to account for the broader impact across communities: for example, the extent of collaboration locally with other groups/organisations, regionally with PIs, nationally with other PIs and internationally with other related groups/organisations. A lot of innovative thought was demonstrated on these issues among workshop participants and, where relevant, suggestions have been incorporated into a Logic Model (Table 4.1). The Logic Model provides a framework for presenting the most feasible information by showing all inputs, activities/interventions, outputs, outcomes/impacts and the associated indicators that emerged from the workshops. A full list of all the suggested metrics from the workshops is presented in the appendix (Section A2).

Most significantly, workshop participants stressed that LCGs were particularly diverse, sometimes with a single focus, and therefore participants recommended a group-centred approach to impact measurement at the LCG level. It was seen as helpful for the LCG members and LCWs to concentrate on two main questions: (i) what is (are) the main aim(s) of the LCG, and (ii) what has the LCG achieved in relation to its specified aims over a certain period of time? The workshops identified that there is no single measurement approach that would capture these principal components of performance and impact of LCGs, mainly due to the wide variety of groups supported, the resources/skill-sets of the LCWs, and the different client/target groups they work with. Furthermore, it was suggested that there are broadly two types of LCGs, which could possibly be categorised as 'horizontal' and 'vertical'. ${ }^{26}$ The 'horizontal' LCGs are mainly concerned with engagement, stability and sustainability at a local community level; the 'vertical' LCGs are currently engaged in strategic involvement in policy at a regional and/or national level. We develop this 'horizontal' and 'vertical' classification further to identify the main purpose of the group but, of course, these types of relationships are not mutually exclusive and may change over time. For instance, horizontal relationships play an important role within vertically focused groups.

26 See Conn (2011) for more information on a similar classification in the 'community engagement' literature. 
There was an overall consensus regarding dissatisfaction with the indicators that are currently collected by Pobal for LCGs under Goal 1 and the extent to which the progress of LCGs is being adequately captured under SICAP. Most workshop participants felt that the current metrics collected under SICAP failed to effectively reflect changes in community development and/or the capacity of communities to effect change. Basic information on the number of participants and the number of interventions is currently collected, but a number of weaknesses were identified in this approach. For example, one participant highlighted, with reference to their own locality, that a greater number of participants in one group than in another group does not necessarily indicate a more substantial impact in terms of community development. Another participant suggested that the overall regional participation rate of community members involved in community organisations or LCGs would be more informative as a broad measure of overall engagement, along with some more general demographic information about LCG participants. ${ }^{27}$

A concern was expressed that current SICAP targets and measurement indicators were overly prescriptive and may indirectly provide a disincentive to work with the most disadvantaged members of communities, or those with the most complex needs, requiring more intensive interventions. Furthermore, in line with this, the current metrics were described as overly quantitative and there was a consensus that there should be some rebalancing in order to include additional qualitative measures in the reporting framework. It was felt that using qualitative measures would allow for a more in-depth analysis of the quality of the processes and outcomes involved and for the context within which groups operated to be reflected in the general assessment.

The possibility of extrapolating good practice from a full review of the end-of-year reports, or intermittent thematic reports, was suggested by LCWs as a way of providing a unified view of changes that are occurring in the areas of community development as a result of SICAP. This could be especially useful in the presence of a national programme that is in a position to outline, or focus on, a number of key areas for development. In the Darmody and Smyth (2018) interviews with PIs, CEOs and workers involved in Goal 1 activities of SICAP 2015-2017, CEOs and staff were not always specific about alternative metrics that could be used to capture such community development activities. However, there was a consensus about the need to record qualitative as well as quantitative information and for this to be directly incorporated into recording structures:

Often what happens is they [Pobal] say, 'Just tell us' but, you know, to me it would be easier to have something on the system that you can report on the system. 
It's mainly through having an opportunity to actually detail down what you're actually doing and to actually be able to do that in an easy system.

I understand that the challenge is between the descriptive, the narrative and that you're using a computer system. I understand that and that part of the problem is that we have ... the IRIS system ... it's yes/no and I understand that in terms of capturing it but I think that that section maybe needs to be up-ended and you go back to, you know, the beginning a little bit ... It's issue-based, area-based. There's no way to capture 'well, what is the issue?' ... You could bring in some of the stuff around integration. 'Well, what are the problems that are coming up?' You know ... even if it had words like 'isolation', 'loneliness', those kind of words.

In order to aid evaluation, given the diverse nature of LCGs, a number of participants proposed guidelines regarding a measuring tool to assist selfassessment across the workshops. For example, one LCW reported success using the 'Rickter Scale', which is a 0 to 10 scale measuring personal progress around employability for those seeking work. ${ }^{28}$ This is broadly similar to the concept of an individual distance-travelled tool that is currently being explored by Pobal and the DRCD. The term 'distance travelled' refers to how far an individual progresses towards an outcome such as employability relative to his/her own baseline starting point. The benefit of this approach to measuring whether a programme is successful or not is that while hard outcomes are useful in certain respects, such as course completion, employment and further education training, they are not adequate for capturing progression of individuals who are facing multiple barriers to social inclusion. The distance-travelled tool allows for a more nuanced measure of individual achievement, taking account of the initial starting point of the individual.

The distance-travelled tool has been used extensively; for example, Dewson et al. (2000) use it to model increases in employability; Thomas et al. (2017) used it to model the effect of flexible learning options for disengaged youth in Australia; Triangle Consulting (2012) used it as a way of evaluating 'Growing Our Strengths', a programme for children and vulnerable families. The distance-travelled tool appears to have been used exclusively for applications at the individual level and has not formed part of the monitoring within the SICAP programme until recently. We find no evidence of its application to groups to date.

However, conceptually there is no reason why the distance-travelled approach cannot be developed and used in a similar way for groups. It was suggested that something similar could be developed for LCGs. Importantly, it was felt that 
developing such an approach would lead to systems that are more likely to be fit for purpose, understood and bought into by LCWs and LCG members, who form part of SICAP's central delivery approach. Some suggested inclusions for the LCG distance-travelled model were levels of participation and involvement, increased social contacts, levels of confidence, acquisition of knowledge, communication skills, resources reaching excluded groups and communities, better facilities and services being provided, empowerment, sense of purpose, increased levels of community spirit and organisation, collaboration and community integration, political influence, and general improved levels of community well-being. The distance-travelled tool can have an important role in terms of the impact of policy interventions in community development. However, it is not recommended that the distance-travelled approach be used as a criterion for funding or linked to future funding due to potential perverse incentives and/or ethical concerns.

The LCG members and LCWs consistently stressed that the development of any additional metrics scales and/or questionnaires for evaluation purposes should be accompanied by a process that ensures that the language used is appropriate, clear and non-invasive. Additionally, LCWs highlighted the importance of more inclusive consultation with frontline staff in terms of the metrics to be collected, and emphasised that their expertise, experience and qualifications ensured that they were well equipped in terms of outlining the collective determinants of LCG progress and community level well-being within their geographical areas.

Some LCG members indicated that social media and technology provide them with a set of digital tools to communicate and connect more efficiently and inexpensively with wider networks for support and/or to raise awareness. The use of social media and websites, such as Facebook, Twitter, and Survey Monkey, was proposed to aid measurement of engagement for LCGs in order to easily record and monitor the interactions between individuals and groups using hits, likes, surveys, polls and video views. Indicators of the developments of LCGs at more progressed stages included examples, such as participation in decision-making structures, opening a bank account, developing charity or private limited company status, obtaining additional funding, and being financially viable.

Finally, for many communities, SICAP interventions provide personal and collective advice, support and resources, as well as a defined route to access other service providers and decision makers, such as local authorities, health and welfare bodies. The relationship across the three SICAP goals ${ }^{29}$ in terms of community development was highlighted. For example, there is a strong likelihood that a person can enrol in an educational programme (Goal 2) and then proceed to join an LCG (Goal 1) or vice versa. Furthermore, on joining one LCG, a person could 
become aware of another LCG that appeals to them.

In the Darmody and Smyth (2018) interviews, a dominant theme was the holistic approach implemented to meet the needs of the community:

Community spirit is hugely important for all walks of life, you know, and there are spiralling benefits from that ... I think when you're looking at something like activation in isolation you can't, because even when a person comes in here and they're looking for supports and services around employment, we usually kind of direct them and refer them on to the other supports and services we have here, so everything is interlinked.

Goal 1 can be a referral mechanism into goal 2, goal 3, so that ... there is synergy between the three goals.

The theme of community development needs to be understood as critical to all goals of the programme and not just goal 1, and should underpin how individuals and groups are engaged with.

It's about community workers who are in communities, known by communities in different guises, doing a bit of support here, engaging people somewhere else, doing different things, setting up clubs, setting up groups that meet people's needs as they see them that day. And then ... when somebody turns around and says, 'Well my child has just left school and I don't know what to do with him' or, you know, 'Here's the referral.' And it's a referral from somebody they trust at that stage.

It was also suggested during the workshops that LCGs can sometimes become overly dependent on a select few members, or a select few members can dominate the workings and strategies of LCGs. The possibility of tracking individuals' progress within and across LCGs was suggested but, while interesting, currently this appears too difficult and would necessitate a level of data collection that would potentially be overly burdensome. ${ }^{30}$

Network and training opportunities for LCWs to work in partnership were also seen as important arrangements in order to allow time and resource opportunities to facilitate learning, knowledge sharing and identification of best practice, build a wider collective voice, identify a more effective use of resources and develop a more thorough input to public policy debates. However, due to limited available funding, LCWs have to compete for funding regionally; this has been suggested as one reason why LCWs do not interact: perhaps they sometimes view each other as competitors rather than as possible collaborative partners.

30 Such impacts could potentially be assessed within a thematic qualitative evaluation. 


\subsection{THEME C: IN TERMS OF THE COMMUNITY GROUP PROGRESSION MATRIX, TO WHAT EXTENT IS PROGRESSION THE NORM, AND IS PROGRESSION ALONG THIS MATRIX A TRUE REFLECTION OF CAPACITY BUILDING AT A COMMUNITY LEVEL?}

The community development matrix was created by Area Development Management Ltd (ADM, 1999) and extended by Pobal to provide a framework to assist LCGs with monitoring their development. The first stage is the formation of the group; the second stage involves capacity building and empowerment; the third stage consists of collective action; and the groups that were involved in policy- and decision-making at a local, regional or national level were deemed to be at the final stage, Stage 4 .

The community group progression matrix is shown in Figure 3.1. Workshop participants generally considered that it did not adequately measure the progression of the vast majority of LCGs. It was stressed that the matrix was not a true reflection of progression, or development, given that it is unrealistic to expect all groups to progress in such a linear way. LCG members and LCWs stressed that the reality of community group development is a non-linear, challenging and complex process for many groups, where group members and capacity are often continuously changing. In some cases it was indicated that the stages could be interpreted as interchangeable and not mutually exclusive, i.e. capacity building can happen at Stages 3 and 4 as well as Stage 2 .

\section{FIGURE 3.1 COMMUNITY GROUP PROGRESSION MATRIX}

Stage 1: Pre-development and group formation
Stage 2: Capacity building and empowerment
Stage 3: Collective action
processes at a local, regional and/or national level

One recurrent recommendation was that a more fluid circular progression matrix would be more appropriate for 'horizontal groups', which are likely to remain at the early stages, and would give more advanced groups a realistic focus concerning progression. The importance of the initial set-up of a group regarding its aim was echoed, as was the critical issue that very few LCGs regularly revisit, reconfirm and assess progression in terms of their own core mission. Given that the progression depends on differing initial aims and visions of LCGs, linkages to the progression matrix in its entirety as defined may be very weak. Similarly to the feedback on the indicators and metrics from Theme $B$, it was suggested that different progression measurement tools for distinctive types of groups would seem more sensible. 
Interviewees in the Darmody and Smyth (2018) study were also critical, not only of the nature of recording contact with LCGs in SICAP 2015-2017 but also of the method of capturing the activities and progress of the LCGs themselves. In particular, it was felt that recording the 'stage' of the LCG in terms of the specified template, i.e. progression matrix, did not adequately reflect the goals and progress of that group. Staff felt that some groups had a specific purpose that was valuable in its own right, but these groups would never 'progress' to involvement in decision-making at regional or national level.

The ultimate outcome for a group in the programme is that they are strategic players at national level. Now most of the community groups in this city have no interest in being a strategic player at a national level; they want to run a crèche, or they want to run the field, or they want to provide adult education classes.

The community work isn't ... that linear. It doesn't work like that ... You're going to have certain groups that are always going to be at that stage but ... it's vital in a community in a well-functioning community setting, you know, that there's civic minded people that can come and they meet ... from 10 to 12 every Thursday morning for, you know, till the end of time. Rather than you're building people up so that they then are happy to stand outside the Dáil campaigning and sort of thing.

This approach was seen as failing to capture important progress in the establishment and formation of LCGs:

One goal is what path of development are they at ... I'd like that to be maybe broken down again. So, if I'm measuring that, I can actually see how ... they've now become their own committee. They've now opened a bank account.

Group formation was viewed as a long-term process and thus not adequately captured within an annual reporting structure:

Initially an organisation or a set of people will come together and they're going to be pretty informal and they're going to be unstructured. So ... an initial support in their case I think needs to be around the idea of their governance and their structure and ... how they organise themselves. Then ... only when that's kind of settled can you then move on to the point of, okay, what now do you want to do and how can you do that, and then you're into the area of having to have the structure in place and the ability to maybe have a bank account and manage money and stuff like that before we can begin to do stuff. And it's then that the level and the intricacy or the complexity or the scale of what the organisation is able to do is a measure of their 
ability. So, if you have a body that's able to organise itself and use, bring in, we'll say, or organise events or activities for its target group for whatever, for young people or whatever, well, then that's fine. But then when do they get to the point where they're going to be of a scale that they could begin to maybe look for substantial resources to build a youth centre? You're talking about years down the road. So I think the progress of community structures has to be measured by their capacity to do more complex and interesting and innovative things over time.

During the consultative workshops, in line with this, the first stages - (1) predevelopment and group formation and (2) capacity building and empowermentwere agreed to be appropriate for almost all groups. Stage 3, collective action, was described as something that many groups would strive for but, in some cases, would not be achievable or possible. Stage 4 , strategic involvement in policy- and decision-making processes at a local, regional and/or national level, was described by participants as only suitable for a small proportion of LCGs. For example, Stage 4 may not be an aim for a knitting group, gardening group, bowling group, or other groups classified as 'horizontal' above, whereas it may certainly be an aim for a homeless service, disability interest group, cancer support group, local drugs task force, active retirement association, equality working group, domestic violence support group/service, or other groups classified as 'vertical'. Furthermore, there is apprehension in some cases for LCGs progressing to Stage 4, as this can somewhat remove the LCG from the community, creating a representative vacuum.

The fact that the progression matrix fails to be highly relevant for the vast majority of LCGs is further evident when we examine the stages of development that LCGs were at upon registration in the IRIS database for 2016 (Table A1.3). Most groups (46 per cent) were at Stage 2 of the matrix, capacity-building and empowerment. Just over one in four of the LCGs were at the stage of pre-development and group formation, while less than 1 in 10 groups were at the final stage of the matrix, strategic involvement in policy-/decision-making. ${ }^{31}$

\subsection{THEME D: HOW CAN WE IMPROVE THE EXISTING APPROACH TO DATA COLLECTION IN ORDER TO MORE ACCURATELY REFLECT CHANGES IN COMMUNITY DEVELOPMENT IN AREAS SUPPORTED BY SICAP?}

Given that this final theme was particularly broad, a number of issues previously discussed in the workshops under the other themes ( $A, B$ and $C$ ) were reiterated. ${ }^{32}$

\footnotetext{
31 It is expected that just a small percentage of groups will participate in the final stage due to the local nature of most of the groups that SICAP supports.

32 See appendix, section A3 for a more detailed summary.
} 
In this section, we emphasise additional items that were introduced here in the context of improving the existing approach to data collection.

A number of recommendations were made around the importance of communicating and displaying to LCWs and LCG members the value of data collection and how it is used, for example, through the wider dissemination of reports etc. It was suggested that steps be taken to increase clarity on data usage, and progress be made in refining and reducing the collection of data to questions that are most relevant to understanding the key issues. It was felt that more attention needed to be given to limiting the gathering of data with more accuracy than is needed, which relates to the notion of 'optimal ignorance' discussed in Chapter 2.

Concerns regarding data security and data protection were also expressed in this regard, mainly by LCG members. Also, the possibility of sharing information across departments and the value of developing a common national framework in relation to effective community development in Ireland was suggested. The workshop participants referred to the 'Healthy Ireland Initiative' co-ordinated by the Department of Health as an example of a framework that aimed to take a whole-of-government and whole-of-society approach to improving health and well-being and the quality of people's lives.

A common critique from LCG members and LCWs was that the language, terminology and questions used for data collection purposes were often overly complex, especially for individuals experiencing difficulties with literacy. It was recommended that the language used be simplified and care taken to ensure that it is more accessible, with an increased understanding of individuals' sensitivity surrounding their personal data. For example, LCWs suggested that requests for invasive information on an initial meeting, without time to build a rapport, can create a barrier to engagement and discourage people from attending.

The lack of qualitative data currently collected was seen as a real concern by community workers, who also felt that the use of narratives and milestones in quarterly reports could better reflect the nature of their work within communities. The fundamental contextual information necessary for any evaluation process was reported to be minimal in the current data collection process. This contextual information was seen to be vital in order to capture the intensity of work at a local level and to appreciate the challenges of working successfully with particularly hard-to-reach groups. For example, those working within public service provision, community and the voluntary sector consider Roma a 'hard-to-reach group' as they are less likely to access services that might support them in Ireland..$^{33}$ Furthermore,

33 Roma experience barriers to accessing services in Ireland due to negative experiences in their home countries; distrust; language barriers; lack of knowledge about services; and cultural differences (Pavee Point, 2018). 
a greater appreciation of the pace of change and appropriate time frames for evaluation was seen as crucial.

It was stated that the process of building relationships in community development is central to progression and can be extremely time-consuming. Community workers expressed frustration with what they felt was the unrealistic and simplistic expectation that local community groups were already in existence and in a position to readily progress along the community progression matrix. It was reported that divergence between targets and actuals can potentially lead to superficial work and less concentration on hard-to-reach groups.

The current requirement for two interventions with an LCG in order for the group to be accounted for in the PI's key performance indicators (KPIs) may create perverse incentives. In fact, it was suggested that some interventions are not being recorded within IRIS due to both the requirement of two interventions and the overall volume of data recording being too high. In addition, LCWs saw the current duplication of input, in terms of office hard copies and soft copies within the IRIS database, as overly burdensome and completely unnecessary.

Furthermore, interviewees involved in the Darmody and Smyth (2018) study felt that targets for SICAP 2015-2017 in terms of the LCGs placed a greater emphasis on numbers than on the quality of community engagement at local level:

You shouldn't be creating new groups all the time in community development, you should be consolidating. In actual fact, probably if things were progressing ... you might get a smaller number of groups over time, but they might be more functional.

In addition, one-off events designed to promote community integration were not recorded through IRIS. ${ }^{34}$

They are key pieces of work we carry out also throughout the year, you know; for example, International Women's Day... We didn't count that and I mean I don't think that's recorded anywhere really. It certainly isn't recorded on IRIS, you know. A group didn't form, it wasn't a course ... we brought women together to celebrate diversity and did a few things over an evening so that's very simple, just a simple example.

LCGs were seen as very diverse in terms of the support they required. As a result, many kinds of supports ranging from ongoing phone calls around practical issues to highly intensive work with some groups could not be captured within the IRIS system:

34 There is a facility on IRIS to record one-off events under the 'non-caseload supports and outputs' category. 
Our community development work, an awful lot of that, you know, isn't recorded through SICAP, you know, like for some groups that are in great need or that we would provide a huge amount of support, you know, you could chat with members of one group a couple of times a day, you know, it varies. People could ring you or you could, you know, so there could be a huge ongoing support given to a particular group over a period of time. You just don't record all that, it's just not possible as an intervention each time, so there's a huge amount of interventions not recorded, I would say, through the Goal 1 because it's just not practical really.

I'd say we probably hit eight to ten interventions with each group. It's not two. Like, to me that's not what it's about.

Each one of them [LCGs] must be registered, formally registered and we must meet with them at least twice. Now, for some of them that's fine because we might have a group who might ring us and say, you know, 'We're from this residents' association or mental health association, we need someone to come and talk to us about', you know; we might do a strategic plan, governance and guidance and ... they just need that advice and guidance for one or two meetings. But then there are other community groups where our staff traditionally would have been on their bottom tier boards of management, guiding them all along and helping to do a lot of work with them.

Interviewees were cognisant of the need for accountability and measurement but generally felt that the richness and intensity of the work was not well captured through IRIS or other mechanisms. Indeed, many interviewees reported keeping records for their own purposes that were not fed into IRIS. This ranged from records of one-off dealings with individuals (where it was not felt worthwhile to engage in the registration process) to detailed notes or case studies on LCG activities and progress.

It's only in my notes down the side ... They [Pobal] don't read that ... It's nearly a story. I'm trying to capture that in the files but ... it is a story but it doesn't capture the story.

Finally, in the workshops, investment in community development training by Pobal to enhance the expertise, knowledge and collaboration of frontline staff was viewed by LCWs as crucial in order to improve the existing approach to data collection to more accurately reflect changes in community development in areas supported by SICAP. It was felt that national-level thematic studies would allow PIs and LCWs to demonstrate developments using local case studies, and that data collection and evaluation should truly reflect what is valuable for communities (for example, respect, inclusion, empowerment, equality, listening). Aligning this with what is viewed as valuable to funders was seen as one of the key obstacles. The sector has experienced a high degree of budget cuts over the past decade, and 
LCW and LCG members expressed concern that LCGs will decrease due to new governance structures concerning data protection, insurance and responsibility, and lack of support in these areas.

\subsection{CONCLUSION}

This chapter summarises the qualitative research conducted, focusing on the feedback from the consultative workshop with members of LCGs, LCWs and other stakeholders. In terms of an overarching framework, there was a consensus in support of an approach similar to the Logic Model whereby processes and outcomes are specific to the supports and outcomes of SICAP. However, a key issue identified with this approach was the inability to directly attribute SICAP funding to any particular outcome, or impact, given the multiplicity of funding in the community development space. Due to the existence of different streams of funding and the complexity of the system described, the expectation of measuring any causal influence of SICAP on community-level outcomes is unrealistic.

Community workers and LCG members emphasised the need for the overall cost of evaluation to be reasonable and balanced against the overall investment in a community development programme. The importance of qualitative measures such as case studies was highlighted, along with the resource and time requirements and additional administrative burden placed on staff in order to document the information as required.

There was an overall consensus regarding dissatisfaction with the indicators that are currently collected for the programme for LCGs under Goal 1 and the extent to which the progress of LCGs is being adequately captured under SICAP. Workshop participants generally considered the community group progression matrix ineffective in terms of adequately measuring the progression of the vast majority of LCGs. The lack of qualitative data currently collected was seen as a real concern by community workers, and it was felt that the use of narratives and milestones in quarterly reports could better reflect the nature of their work within communities.

SICAP 2018-2022 represents an opportunity to develop metrics that better capture the complexity of the work. It may be possible to collect broad metrics relevant to all groups for use within a Logic Model framework, for monitoring, but additional information and approaches are necessary to more fully measure the impact of SICAP in this way. Two specific suggestions discussed at the workshops were a distance-travelled measurement tool for LCGs and intermittent systematic thematic reports. 


\section{CHAPTER 4}

\section{Conclusions}

\subsection{INTRODUCTION}

This report is part of a broader ESRI-Pobal joint research programme commissioned by Pobal and funded by the DRCD. The purpose of the research is to inform policy development regarding social inclusion provision at community level. It adopts a mixed-methods approach, combining qualitative and quantitative analysis, to examine the extent to which community development programmes in Ireland can or should be subject to evaluation, with a particular focus on SICAP 2015-2017. The report draws on a rich body of information, including consultation workshops with members of LCGs, LCWs and other key policy stakeholders and an analysis of administrative (IRIS) data. This chapter highlights the main themes emerging from the research before discussing the implications of the findings for the future development of SICAP.

\subsection{A CONCEPTUAL FRAMEWORK FOR MONITORING}

Evaluating how deeply a community development approach is impacting participants and the wider community is a complex task. Outcomes of community development approaches are often difficult to measure, because in essence they deal with social relationships and the complex functioning of groups and communities. Emphasis is placed on empowerment, increased levels of community spirit and mobilisation, and improved levels of community well-being generally.

Within the general academic and policy literature, a number of conceptual approaches have been suggested to provide an overall framework to guide decisions around the metrics to be collected in any assessment of community development (Logic Model, four-pillar approach, ABCD model, LEAP framework). Each of these theories generally involves a clear statement of the programme objectives, which are then linked explicitly to inputs and outcome variables that the policy should be influencing. The research shows that the development of an approach similar to the Logic Model for SICAP would be helpful in terms of monitoring progress, whereby the specified processes and outcomes are related precisely to the goals of SICAP.

It is important to have such a systematic framework in place in terms of monitoring; however, monitoring and the evaluation of causal influences are two very different concepts. Tools, such as the Logic Model, proposed here (see Table 4.1) provide a useful framework for monitoring interventions and are not a means of measuring causal relationships in the context of SICAP. 
Inputs

\section{What resources go into a} programme?

Human resources (time invested by staff,

volunteers, partners and local people)

Financial resources (SICA funding, grants, donation

and user fees)

\section{Activities}

\section{What activities does the}

programme undertake?

Intervention(s) by SICAP to help

LCG members to gain knowledge

and skills (capacity-building)

Intervention(s) by SICAP to determine the LCG's aims and goals and develop a strategic plan for the LCG

Facilities and equipment

Intervention(s) by SICAP to assist the LCG to promote engagement

Knowledge and skills base (community workers, other staff and members of LCGs)

Intervention(s) by SICAP to assist the LCG to implement its strategic plan

Intervention(s) by SICAP to assist the LCG to participate in local,

Research base (interna and external) regional and national activities

Involvement of collaborators (local, state, national agencies and other organisations) individuals or LCGs to advocate for

their interests. Increased interagency responses to local needs

Intervention(s) by SICAP to assist the LCG to monitor and evaluate its progress

NOTE: Intervention type (one-toone meeting, group meeting, workshop, information session, etc.) and duration can be recorded
Outputs

\section{What is produced through those} activities? (Short-run)

Increased share of individuals within the local community involved in LCGs particularly the hardest to reach in the most disadvantaged areas)

Increased engagement of SICAP staff with local community members

(particularly the hardest to reach in the most disadvantaged areas)

SICAP target groups have greater representation and participation in decision-making structures at a local, regional and national level

Strengthened LCGs and local communities

Improvements in the well-being of local persons through increased resources, facilities, services, etc. brought about by active engagement of citizens

Increased individual, organisational and community capacity and higher engagement by service providers in local communities

Improved communication among diverse individuals and groups in the population

Increased level of satisfaction expressed by the participants in the programme
Outcomes/Impacts

What are the changes/benefits that result from the programme? (Long-run)

Increased engagement of local community members (particularly, the hardest to reach in the most disadvantaged areas)

Increased links between LCGs, local service providers or other statutory and key providers

Increased participation in local, regional and/or national decision-making structures; greater citizen engagement in line with national policy

LCGs have greater capacity to address the needs of the disadvantaged communities they represent

Increased uptake of mainstream services by disadvantaged individuals; improved economic conditions (increased income, increased financial stability and/or reduced economic inequality)

Improved social conditions (reduced crime and violence; improved co-operation and social connectedness)

Increased networks; greater sense of collective efficacy; greater respect for the individual and for diversity, equality and cultural difference

Greater participation in democratic processes
Programme indicators

\section{Quantitative measures}

No. of LCGs assisted under SICAP in Goal 1 (including level of intensity) No. of members assisted by the LCGs No. of target groups represented in LCGs

No. of LCGs collaborating with other LCGs, local service providers or other statutory and key providers

No. of LCGs whose members have been assisted by SICAP to participate in local, regional or national decision-making structures (including level of intensity)

Progression matrix as suitable for some LCGs; no. of LCGs assisted by SICAP to leverage funding (amount of funding)

Increased contacts with social services; percentage of people in poverty and/o with high deprivation levels; mean and median income; share of unemployed individuals

Frequency of meetings for LCGs; presence of support networks; no. of LCGs

collaborating with other LCGs, local service providers or other statutory and key provider; crime rates

Share of individuals within the local community involved in LCGs; share of individuals from target groups involved in LCGs in the local community

Share of individuals registered and participating in local and national elections; share of target groups participating in key institutions, organisations, or boards 


\subsection{CHALLENGES WITH MEASURING CAUSAL RELATIONSHIPS USING AGGREGATE OUTCOMES}

A fundamental issue identified by the research was the difficulty of attributing SICAP funding to any particular outcome, or impact, given the multiplicity of funding in the community development space. This is highlighted in the existing data; for example, in 2016, SICAP funding was found to account for a minority proportion of the funding for the majority of programme implementers (PIs), which makes separating out causal impacts impossible. Darmody and Smyth (2018) analyse the financial reports for PIs in 2015 to determine that approximately half of PIs received a fifth or less of their funding through SICAP and only one-tenth received at least half of their funding through SICAP. Due to the different streams of funding and the complexity of the system, the expectation of measuring any causal influence of SICAP on community-level outcomes is unrealistic. ${ }^{35}$

In Ireland and internationally, there is a limited culture of evaluating programmes in the community development sphere. Therefore, quantitative elements of the evidence base are limited and there is no systematic set of numerical indicators by which to measure impacts. Furthermore, the long-term consequences of a programme, e.g. reduced poverty rates, can be very difficult to ascertain since several other projects, similar or dissimilar in nature, can potentially lead to the same impact. When considering the evaluation of community development programmes, it must be borne in mind that disadvantaged individuals, families and communities may take part in numerous programmes and be recipients of multiple services, many of which have varying time frames. Therefore, community impact may be able to capture the cumulative effect of these measures rather than the impact of a single programme.

The study concludes that Census information, even at small-area level, is only useful to capture the impacts of all activities, carried out by all actors, in the area, in the presence of an overarching multi-agency approach. It is not possible to attribute community development in an area solely due to SICAP given the range of other programmes present in the area. It was suggested that a unified framework whereby all agencies work towards a common set of clearly defined goals, informed by a common understanding of community development, could be implemented. However, this is not a situation that prevails in Ireland or anywhere else, to our knowledge. Furthermore, the collection of such broad measures of community development would pose particular challenges such as establishing baseline data as a benchmark across locations and the inability to capture potential spill-over effects.

35 Examples of funding streams include Tús, Jobs Clubs, Local Employment Service (LES), Community Employment programme, Health Service Executive, Early Childhood Initiative, philanthropic funding and business funding (Darmody and Smyth, 2018). 


\subsection{MEASURING THE IMPACTS OF LCGS}

Given that it is almost impossible to measure the impacts of expenditure across broad indicators of community development such as reduced poverty rates or increased community well-being, it may be more convincing to measure the impact on LCGs. However, this is also challenging. While it may be possible to collect broad metrics relevant to all groups for use within a Logic Model framework, additional information and approaches are necessary to more fully measure the impact of SICAP in this way. Two suggestions discussed at the workshops and outlined below seem to warrant further consideration: a distance-travelled measurement tool for LCGs and thematic reports. ${ }^{36}$

Due to the diverse needs of different localities and the heterogeneous nature of LCGs, a 'one-size-fits-all' approach to measuring community development at LCG level is not practical. A fundamental issue raised by workshop participants was the need for local flexibility in order to facilitate motivation and participation at the local level. Given that LCGs are particularly diverse, often with a single focus, a group-centred approach to impact measurement is considered most appropriate for monitoring at the LCG level, explicitly incorporating the objectives of each LCG.

In order to aid evaluation using such a group-centred approach, a number of workshop participants proposed guidelines regarding a measuring tool to assist self-assessment by LCG members and LCWs for LCGs. The concept is broadly similar to that of an individual 'distance-travelled tool' that is currently being explored by Pobal for individuals, which often utilises a 0 to 10 scale for measurement across a number of relevant variables. A comparable measurement tool could potentially be applied to LCGs. Such an approach would lead to systems that are more likely to be fit for purpose, understood and bought into by LCG members and LCWs which form part of SICAP's central delivery approach. It is important to note that workshop participants advised that the development of any additional metrics, scales and/or questionnaires should be accompanied by a process involving LCWs and members of LCGs to ensure that the approach and language used are appropriate, clear and non-invasive.

The second suggestion was the inclusion of more qualitative measures to allow for a more in-depth analysis of the quality of the processes and outcomes involved, and for the context within which groups operated to be reflected in the general assessment. The systematic extrapolation of good practice from intermittent thematic reports and/or a full review of the end-of-year reports would provide a unified view of changes that are occurring in the areas of community development as a consequence of SICAP. These more fully reflect the varying objectives and activities of LCGs. This would be especially useful in the presence of a national

36 Pobal has recently agreed to implement a distance-travelled tool and thematic reports with LCDCs and the DRCD. 
programme with a specified time frame that is in a position to outline, or focus on, a number of key areas for development.

It is important to note that a challenge of such bottom-up approaches to the evaluation of SICAP, and other programmes within the community development sphere, is the comparability of evaluations across Pls and the incentive for PIs to amplify or inflate the value of their programme spending. Subjectivity bias can arise when stakeholders play such a central role in the monitoring and assessment processes. To ensure an appropriate assessment, intermittent independent monitoring, preferably by a third party, can be used with a combination of assessment approaches, i.e. qualitative and quantitative analysis of key metrics (informed by the Logic Model approach) to obtain a balanced and objective view of progress.

\subsection{LIMITATIONS OF THE CURRENT DATA COLLECTION APPROACH}

A dominant issue raised in the research was dissatisfaction with the indicators that are currently collected under SICAP for LCGs under Goal 1 and the extent to which the work and progress of LCGs and LCWs are being adequately captured under SICAP. Most workshop participants felt that the current metrics collected under SICAP failed to effectively reflect changes in community development and/or the capacity of communities to effect change.

Workshop participants generally considered the community group progression matrix ineffective in terms of measuring the progression of the vast majority of LCGs. It was stressed that the matrix was not a true reflection of progression or development, given that it is unrealistic to expect all groups to progress in such a linear way. LCG members and LCWs stated that the reality of how LCGs evolve is non-linear, and quite a complex process for many LCGs, with group members and capacity continuously changing.

Workshop participants described the current metrics as overly quantitative and there was a consensus that there should be some rebalancing in order to include additional qualitative measures in the reporting framework. It was argued that such a rebalancing would allow for a more in-depth analysis of the intensity and quality of the processes and outcomes involved, and reflect more accurately the context in which groups operate. The suggestion for occasional systematic thematic reports, outlined in Chapter 3, directly relates to addressing this criticism. The development of SICAP 2 represents an opportunity to develop metrics that better capture the complexity of community development work. 


\subsection{CONCLUSION}

A host of potential indicators for measuring community development emerged from the workshops. ${ }^{37}$ Quantitative indicators proposed included the frequency, type and duration of interventions and the number of group collaborations and/or networks formed. However, a need for more qualitative measures through the use of surveys, case studies, reports and interviews with key stakeholders was emphasised. There was a desire for indicators to be specific to the groups, taking account of their diverse nature and the fact that they may contain hard-to-reach members. This could be achieved through the use of a 'community tape measure' or a distance-travelled tool, allowing progress to be measured relative to a unique group-specific initial position. There was a consensus that measuring the effect of SICAP on community development would prove difficult due to the existence of a range of funding streams and the complexity of the funding system.

Finally, given that the sector has experienced a high degree of budget cuts over the past decade, resources and cost considerations were a key feature of the research. LCWs viewed investment in community development training by Pobal to enhance the expertise, knowledge and collaboration of frontline staff as crucial. Furthermore, community workers and LCG members emphasised the need for the overall cost of evaluation to be reasonable and balanced against the overall investment in a community development programme. McGuinness et al. (2016) suggest also that the cost of any additional data collection and qualitative assessment has to be considered against the overall cost of the programmes.

In summary, as highlighted by previous research and the lack of evaluations in this area, it is extremely difficult to capture the impacts of activities and spending that occur at the community level. However, there is strong willingness on the part of LCWs, members of LCGs and other key policy stakeholders to implement methods that are appropriate both for the interests of marginalised communities and groups and for the needs of the state and other funders. 


\section{REFERENCES}

ADM (1999). Community development strategies and actions within the Integrated Local Development Programme, Insights No. 11, Dublin: Pobal.

All Ireland Endorsement Body (2011). All Ireland standards for community work, Galway: Community Work Ireland. http://communityworkendorsement.com/wpcontent/uploads/2011/01/All-Ireland-Standards-for-Community-Work.pdf. Accessed on 20 September 2018.

Bamber, J., S. Owens, H. Schonfeld, D. Ghate, and D. Fullerton (2010). Effective community development programmes: a review of the international evidence base, Dublin: Centre for Effective Services.

Barr, A. and J. Dailly (2007). LEAP step-by-step: an introductory guide to the LEAP framework (2nd ed.), London: Community Development Foundation.

Barr, A. and S. Hashagen (2000). ABCD handbook: a framework for evaluating community development, London: Community Development Foundation.

Conn, E. (2011). 'Community engagement in the social eco-system dance', in A. Tait and K.A. Richardson (eds), Moving forward with complexity, Litchfield Park, AZ: Emergent Publications, pp. 285-308.

Darmody, M. and E. Smyth (2018). The goals and governance of the Social Inclusion and Community Activation Programme (SICAP) 2015-2017: a mixed methods study, Research Series No. 68, Dublin: The Economic and Social Research Institute.

Dewson, S., J. Eccles, N.D. Tackey, and A. Jackson (2000). Guide to measuring soft outcomes and distance travelled, Brighton, UK: Institute of Employment Studies, http://www.employabilityinscotland.com/media/83581/guide-to-measuring-softoutcomes-distance-travelled.pdf. Accessed on 14 September 2018.

European Commission (2014). Community-led local development: Cohesion Policy 20142020. Brussels: European Commission.

http://ec.europa.eu/regional_policy/sources/docgener/informat/2014/communit y_en.pdf. Accessed on 20 September 2018.

Fabusuyi, T. (2018). 'Is crime a real estate problem? A case study of the neighbourhood of East Liberty, Pittsburgh, Pennsylvania', European Journal of Operational Research, Vol. 268, No. 3, pp. 1050-1061.

Frechtling, J.A. (2007). Logic modeling methods in program evaluation, San Francisco: Jossey-Bass.

Haase, T. and J. Pratschke (2012). The 2011 Pobal HP deprivation index for small areas (SA). http://trutzhaase.eu/wp/wp-content/uploads/HP-Index-2011-SA-AnIntroduction-02.pdf. Accessed on 20 September 2018.

McGuinness, S., A. Bergin, and A. Whelan (2016). An exploration of (area-based) social inclusion and community development training programmes in Ireland, ESRI Research Series No. 54, Dublin: The Economic and Social Research Institute.

McGuinness, S., A. Whelan, A. Bergin, and J. Delaney (2016). Profiling barriers to social inclusion in Ireland: the relative roles of individual characteristics and location, ESRI Research Series No. 71, Dublin: The Economic and Social Research Institute. 
McKenna, R., V. Bertsch, K. Mainzer, and W. Fichtner (2018). 'Combining local preferences with multi-criteria decision analysis and linear optimization to develop feasible energy concepts in small communities', European Journal of Operational Research, Vol. 268, No. 3, pp. 1092-1110.

Midgley, G., M.P. Johnson, and G. Chichirau (2017). 'What is community operational research?', European Journal of Operational Research, Vol. 268, No. 3, pp. 771783.

Milstein, B. and T. Chapel (2011). The Community Tool Box: Developing a Logic Model or Theory of Change. Lawrence, KS: University of Kansas. http://ctb.ku.edu/en/tablecontents/sub_section_examples_1877.aspx. Accessed 1 August 2017.

Motherway, B. (2006). The role of community development in tackling poverty in Ireland, Dublin: Combat Poverty Agency. www.combatpoverty.ie/publications/TheRoleOfCommunityDevelopmentLiteratureReview_2006.pdf. Accessed 1 August 2017.

Ollerton, J. and R. Black (2017). Planning for social inclusion in playspaces: an evaluation of Livvi's Place, Port Macquarie, Albury-Wodonga, Australia: Institute for Land, Water and Society, Charles Sturt University. www.csu.edu.au/_data/assets/pdf_file/0007/2910652/Report-109-Planningfor-Social-Inclusion-Livvis-Place.pdf. Accessed on 20 September 2018.

Pavee Point (2018). Roma. Dublin: Pavee Point. http://www.paveepoint.ie/what-wedo/programmes/roma/. Accessed 20 May 2018.

Pobal (2016a). SICAP: programme requirements 2016. Dublin: Pobal. www.pobal.ie/Beneficiaries/SICAP/Documents/SICAPProgrammeRequirements20 161.4FINAL(Clean).pdf. Accessed 1 August 2017.

Pobal (2016b). End of year report. Dublin: Pobal. www.pobal.ie/app/uploads/2018/06/SICAP-2016-End-of-Year-Report-FullVersion.pdf

Pobal (2018). SICAP: programme requirements 2018. Dublin: Pobal. www.pobal.ie/app/uploads/2018/05/SICAP-Programme-Requirements-20182022-V1-1.pdf. Accessed 14 September 2018.

Pritchard, D. and A. Kazimirski (2014). Building your measurement framework: NPC's four pillar approach, London: New Philanthropy Capital. www.thinknpc.org/wpcontent/uploads/2015/04/NPCs-four-pillars-summary.pdf. Accessed 1 August 2017.

Purdon, S., C. Lessof, K. Woodfield, and C. Bryson (2001). Research methods for policy evaluation, discussion paper, London: Department of Work and Pensions.

Rossi, P. and H. Freeman (1982). 'Evaluation: a systematic approach', Policy Sciences, Vol. 15, No. 1, pp. 92-95.

STARTTS (2012). Community development evaluation manual: a guide to planning and evaluating community development work with refugee communities, London: New Philanthropy Capital. www.startts.org.au/media/Services-CommunityDevelopment-Evaluation-Manual.pdf. Accessed 14 September 2018. 
Thomas, J., S. McGinty, K.T. Riele, and K. Wilson (2017). 'Distance travelled: outcomes and evidence in flexible learning option', Australian Educational Researcher, Vol. 44, Nos 4-5, pp. 443-460.

Triangle Consulting (2012). GOS evaluation report: outcomes for children and vulnerable families.

www.actionforchildren.org.uk/media/3437/gos_evaluation_report_310512-

1____.pdf. Accessed 14 September 2018.

Vidal, R.V.V. (2009). 'Community facilitation of problem structuring and decision making processes: experiences from the EU LEADER+ programme', European Journal of Operational Research, Vol. 199, No. 3, pp. 803-810.

Wang, Y., A. Touboulic, and M. O'Neill (2018). An exploration of solutions for improving access to affordable fresh food with disadvantaged Welsh communities. European Journal of Operational Research, Vol. 268, No. 3, pp. 1021-1039. 
52 | Valuing Community Development through SICAP 2015-2017 


\section{APPENDIX}

\section{A1 ANALYSIS OF 2016 IRIS LCG DATA}

\section{A1.1 Introduction}

This section describes the main characteristics of LCGs in terms of type, targets, stage of development, progression, number of participants and number of interventions. These data were supplied by Pobal and include information held in the IRIS database in 2016.

\section{A1.2 Number of local community groups (LCGs)}

There were a total of 3,956 groups, with 67 per cent registered in 2015 and 32 per cent in 2016. All groups are used in the analysis in this section.

\section{TABLE A1.1 NUMBER OF LCGS BY YEAR OF REGISTRATION}

\begin{tabular}{|l|c|c|}
\hline Year of registration & $\boldsymbol{N}$ & $\boldsymbol{\%}$ \\
\hline Pre-2015 & 9 & 0.2 \\
\hline 2015 & 2,658 & 67.2 \\
\hline 2016 & 1,275 & 32.2 \\
\hline 2017 & 14 & 0.4 \\
\hline Total & 3,956 & 100 \\
\hline
\end{tabular}

\section{A1.3 Type of LCGs}

Almost two-thirds of groups were registered as both issue- and area-based. The proportions that were solely area- or issue-based were broadly similar at just under 20 per cent. Examples of area-based groups include community radio, festival committees, writers' groups, residents' networks, RNLI and Active Retired Ireland. Examples of issue-based groups are Age Equality Network, Lithuanian Youth Group, Irish Wheelchair Association, Traveller women's groups, and a Syrian group. LCGs that are both area- and issue-based include Community Garden Network, parent \& toddler groups, cricket clubs, mental health groups and Men's Shed.

\begin{tabular}{|l|c|c|}
\hline Type of LCG & $\boldsymbol{N}$ & $\mathbf{\%}$ \\
\hline Area-based & 682 & 17.2 \\
\hline Issue-based & 758 & 19.2 \\
\hline Area- and issue-based & 2,516 & 63.6 \\
\hline Total & 3,956 & 100 \\
\hline
\end{tabular}




\section{A1.4 LCG composition}

Membership of LCGs included all SICAP target groups. ${ }^{38}$ Some LCGs covered more than one target group, while 5 per cent of LCGs did not capture any of the SICAP target groups. Figure A1.1 displays the distribution of target groups among LCGs. The largest single membership across all LCGs was individuals living in disadvantaged areas, with 63 per cent of groups focusing on these. Almost half of all community groups incorporated disadvantaged families, while about a fifth of LCGs involved lone parents and unemployed individuals.

The target group least represented across LCGs was Roma individuals, with just over 1 per cent of groups focusing on it. This reflects the low number of Roma individuals within the population. Groups focused exclusively on disadvantaged areas included groups such as tidy town committees, LGBT diversity groups, and drugs task forces. The 5 per cent of groups that were outside the SICAP target groups included groups such as opera groups, older men's groups, a sports and athletic federation, tourism groups and Birdwatch.

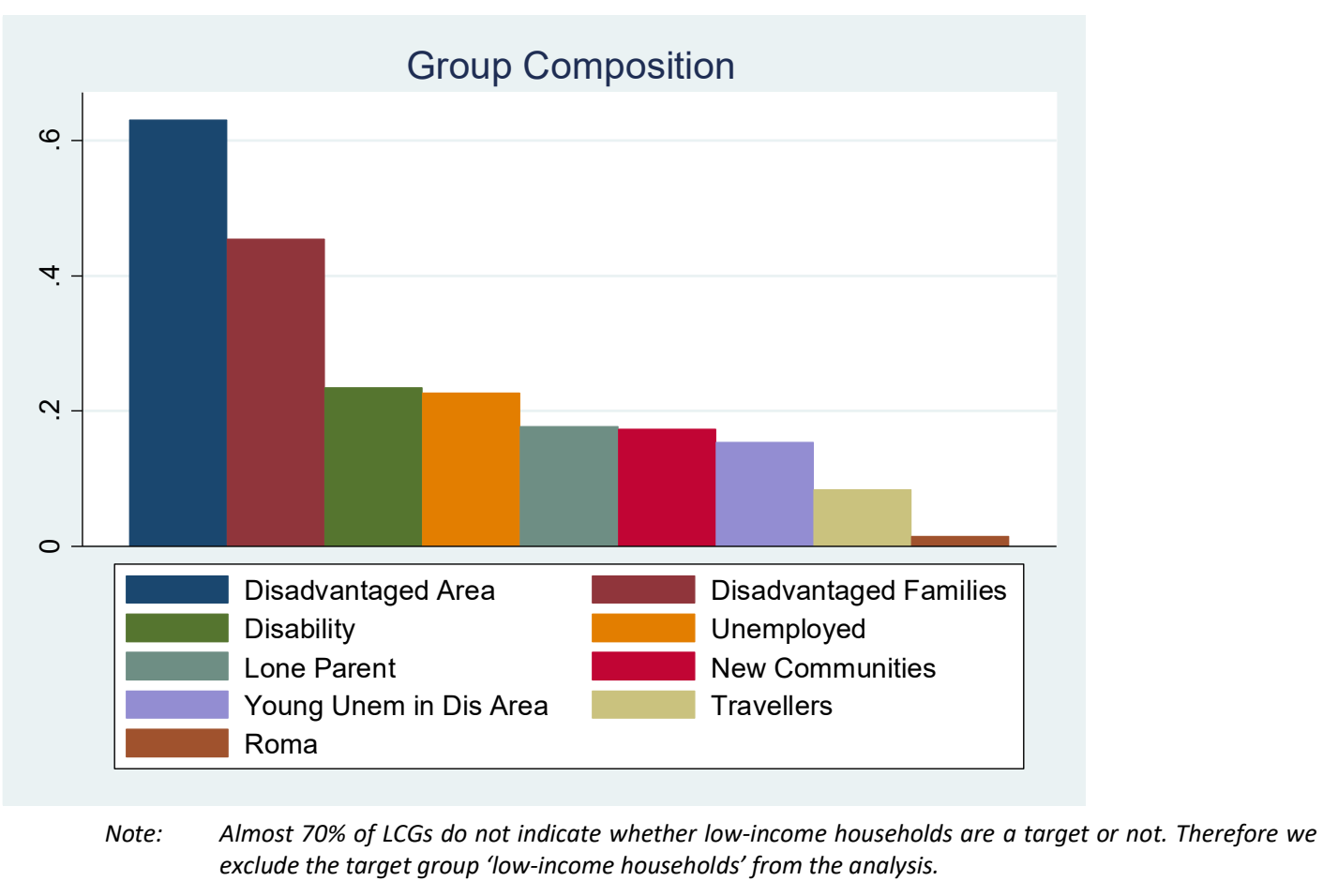

Figure A1.2 illustrates the distribution of SICAP target groups according to the type of LCG. As expected, the target group 'Disadvantaged Area' is more prevalent in area-based groups than in issue-based groups. Similarly, 'Disadvantaged Families'

38 A number of target groups, along with individuals who are living in disadvantaged areas, have been prioritised (Pobal, 2016a). Specific target groups are: children and families in disadvantaged areas; lone parents; NEETs (young people aged 15-24 years who are not in employment, education or training); new communities (including refugees/asylum seekers); people living in disadvantaged communities; people with disabilities; Roma; the unemployed (including those not on the Live Register); Travellers; low-income workers/households; and young unemployed people living in disadvantaged areas. 
and 'Unemployed' have a greater representation in area-based groups. There is little difference across LCG type in terms of 'Lone Parents' or 'Young Unemployed in Disadvantaged Areas' targets. The target groups 'Disability', 'Travellers', 'Roma' and 'New Communities' are more common among issue-based groups.

\section{FIGURE A1.2 DISTRIBUTION OF TARGET GROUPS BY TYPE OF LCG}

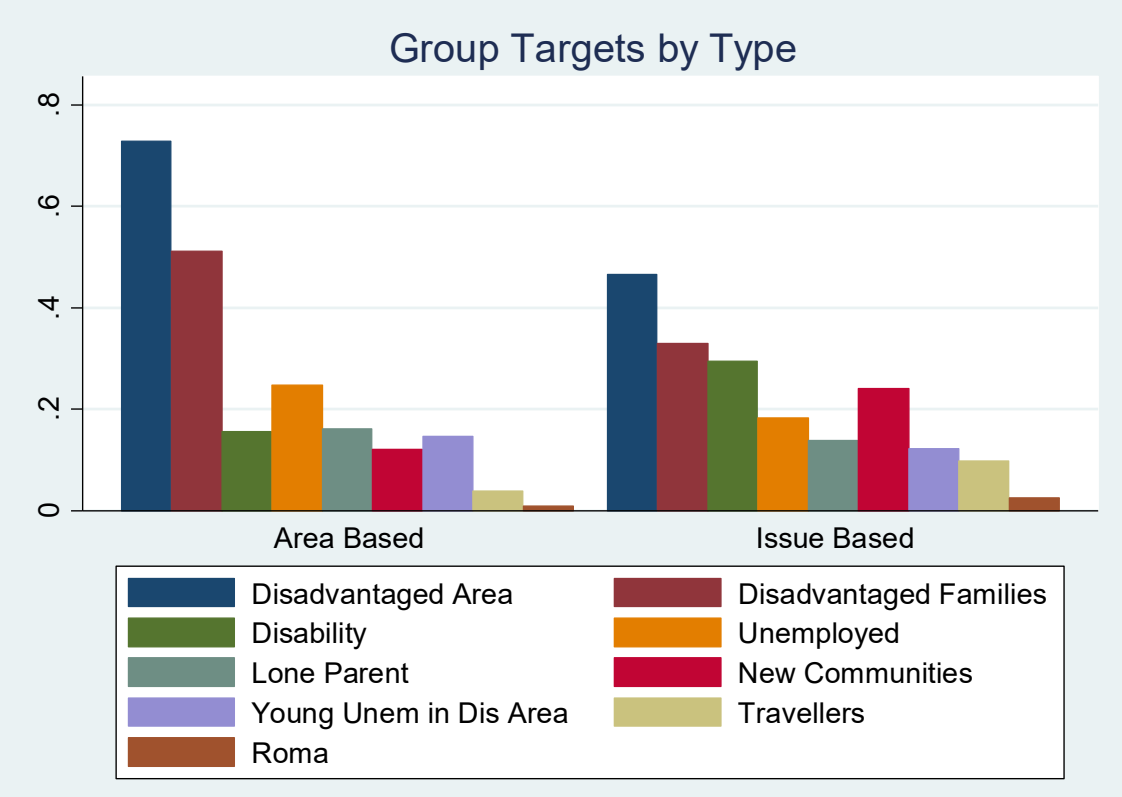

\section{A1.5 Stage of LCGs}

Table A1.3 illustrates the stages of development of LCGs upon registration, using the community group progression matrix. The highest proportion of groups (46 per cent) were at Stage 2 of the matrix, which corresponds to capacity building and empowerment. Just over one in four of the LCGs were at the stage of predevelopment and group formation, while less than 1 in 10 groups were at the final stage of the matrix, strategic involvement in policy/decision-making at local, regional and/or national level.

There was no clear distinction between the types of groups across stages, with many similar groups appearing across all stages; for example, the soccer club was at Stage 1, women's knitting group at Stage 2, boxing club at Stage 3 and bowling club at Stage 4. However, it does appear that LCGs with a broader appeal such as Oxfam, Simon Community and Pavee Point are more likely to appear at Stage 4 of the community development matrix. Ten per cent of groups at the predevelopment and group formation stage progressed to Stage 2, 3 or 4 . 


\begin{tabular}{|l|c|c|}
\hline \multicolumn{1}{|c|}{ Stage of development at registration } & $\mathbf{N}$ & $\%$ \\
\hline 1. Pre-development and group formation & 1,079 & 27.3 \\
\hline 2. Capacity-building and empowerment & 1,817 & 45.9 \\
\hline 3. Collective action & 726 & 18.4 \\
\hline 4. Strategic Involvement in policy/decision-making at local, regional and/or national level & 334 & 8.4 \\
\hline Total & 3,956 & 100 \\
\hline
\end{tabular}

\section{A1.6 Number of individuals represented by LCGs}

Seventy-three individuals were represented or assisted by the average LCG. However, given that five LCGs each reported supporting 10,000 individuals, it is more informative to look at the median and mode. The median number of individuals in a group was 15, which meant that half of groups had 15 or fewer individuals while the other half had more than 15 individuals. The mode was 10 , thus 10 was the number of individuals that had most commonly been assisted by LCGs. Eighty per cent of the groups had fewer than 55 individuals.

The number of individuals in each group differed depending on the type of LCG, with an average of 105 individuals in area-based groups versus 78 in issue-based groups (Table A1.4). When we look at the median and thus limit the impact of extremely large groups, we find that the smallest 50 per cent of area-based groups had 12 individuals while the smallest 50 per cent of issue-based groups had 14 individuals.

\section{TABLE A1.4 NUMBER OF INDIVIDUALS BY LCG TYPE}

\begin{tabular}{|l|c|c|c|}
\hline \multicolumn{1}{|c|}{ LCG type } & \multicolumn{3}{|c|}{ Number of individuals } \\
\hline & Mean & Median & N \\
\hline Area and issue & 63 & 16 & 2,516 \\
\hline Issue & 78 & 14 & 758 \\
\hline Area & 105 & 12 & 682 \\
\hline Total & 73 & 15 & 3,956 \\
\hline
\end{tabular}

The average number of individuals in LCGs tends to increase with the stage they are at in the community development matrix. Table A1.5 shows that there is an average of 38 individuals in groups at the group formation stage, an average of 63 at the capacity building stage, 77 at the collective action stage and 234 at the strategic involvement at local, regional and/or national level. 


\begin{tabular}{|l|c|c|c|}
\hline \multicolumn{1}{|c|}{ Stage of development at registration } & \multicolumn{3}{c|}{ Number of individuals } \\
\hline & Mean & Median & N \\
\hline 1. Pre-development and group formation & 38 & 12 & 1,079 \\
\hline 2. Capacity-building and empowerment & 63 & 17 & 1,817 \\
\hline 3. Collective action & 77 & 15 & 726 \\
\hline $\begin{array}{l}\text { 4. Strategic involvement in policy/decision-making at } \\
\text { local, regional and/or national level }\end{array}$ & 234 & 29 & 334 \\
\hline Total & 73 & 15 & 3,956 \\
\hline
\end{tabular}

\section{A1.7 Number of SICAP interventions by LCGs}

The average number of interventions received by each group in 2015 was 4.3; in 2016 the average was slightly higher at 4.6. The majority of LCGs had two interventions in both 2015 and 2016, consistent with the fact that SICAP specifies a minimum of two interventions for each group before it can be recorded in the IRIS database.

\begin{tabular}{|c|c|c|}
\hline Year & \multicolumn{2}{|c|}{ Number of interventions } \\
\hline & Mean & N \\
\hline 2015 & 4.4 & 2,650 \\
\hline 2016 & 4.6 & 3,263 \\
\hline Total & 4.5 & 5,913 \\
\hline
\end{tabular}

Figure A1.3 illustrates the distribution of LCG interventions in 2015 and 2016. It is evident that the number of interventions has a peak at two and then slowly declines, with most LCGs having fewer than ten interventions and the distribution being similar across the two years.

FIGURE A1.3 DISTRIBUTION OF INTERVENTIONS IN 2015 AND 2016
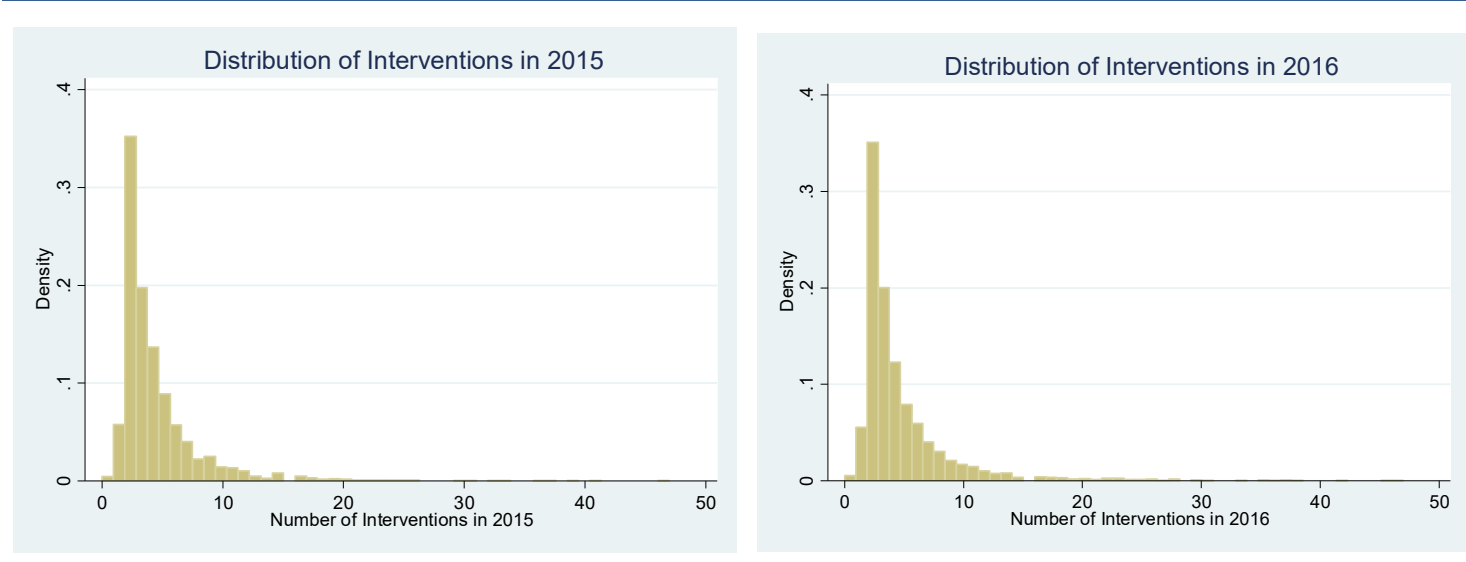

There was not much difference across LCG type in terms of the total number of interventions, with an average of between four and five interventions per group (Table A1.7). 


\begin{tabular}{|l|c|c|}
\hline \multicolumn{1}{|c|}{ LCG type } & \multicolumn{2}{|c|}{ Number of interventions in $\mathbf{2 0 1 6}$} \\
\hline & Mean & N \\
\hline Area & 4.4 & 559 \\
\hline Area and issue & 4.6 & 2,079 \\
\hline Issue & 4.8 & 625 \\
\hline Total & 4.6 & 3,263 \\
\hline
\end{tabular}

Similarly, there was very little difference in number of interventions depending on the stage of development of the LCG, except that the groups at the fourth stage strategic involvement at local, regional and/or national level - had a slightly higher number of interventions.

\section{TABLE A1.8 NUMBER OF INTERVENTIONS BY LCG STAGE OF DEVELOPMENT}

\begin{tabular}{|l|c|c|}
\hline \multicolumn{1}{|c|}{ Stage of development at registration } & \multicolumn{2}{c|}{ Number of interventions in 2016} \\
\hline 1. Pre-development and group formation & Mean & N \\
\hline 2. Capacity-building and empowerment & 5.1 & 892 \\
\hline 3. Collective action & 4.4 & 1,497 \\
\hline 4. Strategic involvement at local, regional and/or national level & 4.3 & 593 \\
\hline Total & 5.2 & 281 \\
\hline
\end{tabular}

\section{A1.8 Distribution of LCGs by HP index}

The HP deprivation index measures the relative affluence or disadvantage of an area using information from previous censuses (Haase and Pratschke, 2012). This index can be broken down into seven categories of disadvantage/affluence. Given that the sample size is quite small (only three groups from 'extremely disadvantaged' areas), we split the areas according to the HP index into three categories: disadvantaged (HP index less than -10), average (HP index between -10 and +10 ) and affluent (HP index greater than 10).

Table A1.9 shows the distribution of type of LCG according to HP index of deprivation measured at the small-area level. ${ }^{39}$ Firstly, it is clear that most LCGs are in less affluent areas, with only 4 per cent of groups in affluent areas and almost 30 per cent in disadvantaged areas. There is no systematic difference in group type according to the HP deprivation index, with the majority of groups in each area being both area- and issue-based.

39 Small areas are areas of population generally including between 80 and 120 dwellings, created by the National Institute of Regional and Spatial Analysis (NIRSA) on behalf of Ordnance Survey Ireland (OSi) in consultation with CSO. Small areas were constructed as the lowest level of geography for the compilation of statistics in line with data protection, and generally comprise either complete townlands or neighbourhoods or parts thereof. A further constraint on small areas is that they must nest within electoral division boundaries. There are approximately 18,488 small area units in comparison to 3,409 electoral divisions. 


\begin{tabular}{|l|c|c|c|c|}
\hline HP deprivation index & \multicolumn{5}{|c|}{ LCG type } \\
\hline & Area-based & Issue-based & Area \& issue-based & Total \\
\hline Disadvantaged & 0.29 & 0.33 & 0.32 & 0.31 \\
\hline Average & 0.68 & 0.66 & 0.64 & 0.65 \\
\hline Affluent & 0.03 & 0.05 & 0.04 & 0.04 \\
\hline N & 682 & 758 & 2,516 & 3,956 \\
\hline
\end{tabular}

Note: $\quad$ The small area HP Index was missing for 813 LCGs. In these cases, we imputed the HP index using the Lot HP Index.

Table A1.10 displays the distribution of HP index across all stages of LCG development. It is clear that the majority of groups are at Stage 2 of the community development matrix and in areas that are neither disadvantaged nor affluent. However, it is also evident that a larger proportion of LCGs at Stage 4 come from less disadvantaged areas compared to groups at stages 1, 2 or 3, with 24 per cent of LCGs at Stage 4 being in disadvantaged areas compared with just over 30 per cent of groups at the earlier stages.

TABLE A1.10 DISTRIBUTION OF HP DEPRIVATION INDEX AND LCG STAGE

\begin{tabular}{|l|c|c|c|c|c|}
\hline HP deprivation index & \multicolumn{5}{|c|}{ Stage at registration } \\
\hline & Stage 1 & Stage 2 & Stage 3 & Stage 4 & Total \\
\hline Disadvantaged & 0.33 & 0.31 & 0.31 & 0.24 & 0.31 \\
\hline Average & 0.63 & 0.65 & 0.66 & 0.71 & 0.65 \\
\hline Affluent & 0.04 & 0.04 & 0.03 & 0.05 & 0.04 \\
\hline$N$ & 1,079 & 1,817 & 726 & 334 & 3,956 \\
\hline
\end{tabular}

Figure A1.11 highlights that LCGs in disadvantaged areas are more likely to include individuals living in disadvantaged areas, disadvantaged families, unemployed individuals, lone parents, young unemployed in disadvantaged areas, and Travellers than LCGs in more affluent areas. Interestingly, a greater proportion of LCGs in affluent areas have individuals from new communities: 23 per cent, compared to 14 per cent in disadvantaged areas. Similarly, a greater proportion of LCGs in more affluent areas capture individuals with a disability: about 21 per cent, compared to approximately 25 per cent in affluent areas. 


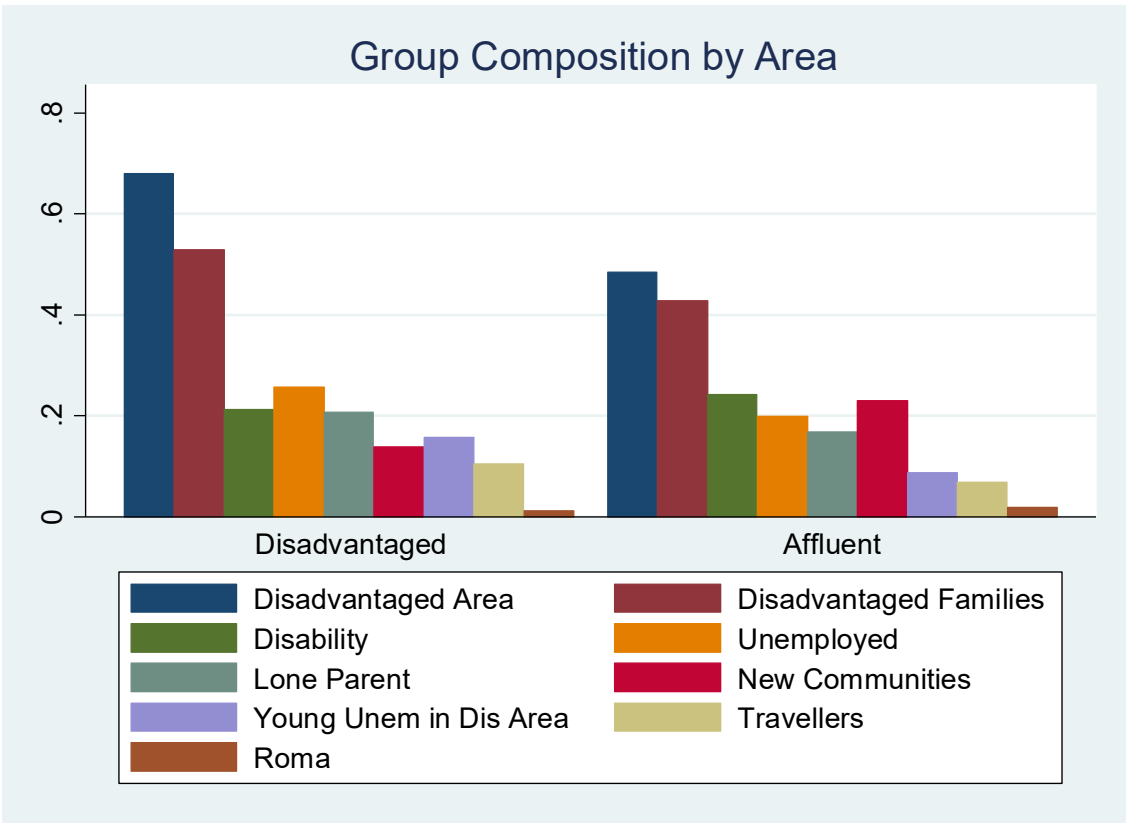

Table A1.11 illustrates that on average, a greater number of individuals are assisted/represented for each group in affluent areas than in disadvantaged areas. The LCGs in neither disadvantaged nor affluent areas tend to have the largest number of individuals.

TABLE A1.11 TOTAL NUMBER OF INDIVIDUALS IN AN LCG BY HP DEPRIVATION INDEX

\section{HP deprivation index $\quad$ Total number of individuals in an LCG}

\begin{tabular}{|l|c|c|c|}
\hline & Mean & Median & N \\
\hline Disadvantaged & 58.0 & 14 & 1,209 \\
\hline Average & 80.5 & 15 & 2,586 \\
\hline Affluent & 74.6 & 20 & 161 \\
\hline Total & 73.4 & 15 & 3,956 \\
\hline
\end{tabular}

Table A1.12 shows that the total number of interventions per group is larger in more disadvantaged areas, with approximately 5.4 interventions on average in disadvantaged areas, 4.4 in areas that are neither disadvantaged nor affluent, and 3.3 in affluent areas.

TABLE A1.12 NUMBER OF INTERVENTIONS PER GROUP IN 2016 BY HP DEPRIVATION INDEX

\begin{tabular}{|l|c|c|}
\hline HP deprivation index & \multicolumn{2}{|c|}{ Number of interventions per group } \\
\hline & Mean & N \\
\hline Disadvantaged & 5.4 & 1,209 \\
\hline Average & 4.4 & 2,586 \\
\hline Affluent & 3.3 & 161 \\
\hline Total & 4.6 & 3,956 \\
\hline
\end{tabular}




\section{A1.9 Group assistance for LCGs}

SICAP helped to support LCGs through a variety of mechanisms. The main avenue was at the pre-development stage, with 92 per cent of groups assisted in their formation, development and progression. A further 34 per cent were assisted to participate in local, regional and/or national decision-making structures, 4 per cent were supported to put anti-discrimination and equality measures in place, 10 per cent were participating in annual planning and review processes for SICAP, and 6 per cent were supported into a public participation network (PPN).

In addition, 9 per cent of LCGs were assisted to leverage funding. The average number of interventions in 2016 was 8.9 for the LCGs that were assisted to leverage funding, compared to 4.5 for those that were not assisted to leverage funding.

There was no difference in level of involvement with LCGs assisted to participate in local, regional and/or national decision-making structures. However, the LCGs that were assisted had an average of 5 interventions in 2016 compared with 3 interventions for LCGs that were not assisted to participate in local, regional and national decision-making structures.

TABLE A1.13 LEVEL OF INVOLVEMENT WITH LCG ASSISTED TO PARTICIPATE IN LOCAL, REGIONAL AND NATIONAL DECISION-MAKING STRUCTURES

\begin{tabular}{|l|l|}
\hline Level of involvement & $\%$ \\
\hline Somewhat involved & 15 \\
\hline Very involved & 15 \\
\hline Extremely involved & 10 \\
\hline Total & 40 \\
\hline
\end{tabular}

Note: $\quad$ This is greater than the $34 \%$ of cases above as some cases have ticked more than one option.

Of the LCGs that were supported into a public participation network (PPN), the majority were somewhat involved (Table A1.14). The LCGs supported into a PPN had an average of 7 interventions in 2016, compared to an average of 4.7 interventions for those that were not supported into a PPN.

TABLE A1.14 LEVEL OF INVOLVEMENT WITH LCGS SUPPORTED INTO A PUBLIC PARTICIPATION NETWORK

\begin{tabular}{|c|c|}
\hline Level of involvement & $\%$ \\
\hline Somewhat Involved & 5 \\
\hline Very involved & 0.8 \\
\hline Extremely involved & 0.2 \\
\hline Total & 6 \\
\hline
\end{tabular}

The highest proportion of LCGs participating in annual planning and review processes (Table A1.15) for SICAP were 'very involved'. The average number of 
interventions in $\mathbf{2 0 1 6}$ for such LCGs was approximately seven, while for LCGs not participating in annual planning and review processes there was an average of five interventions in 2016.

TABLE A1.15 LEVEL OF INVOLVEMENT WITH LCGS PARTICIPATING IN ANNUAL PLANNING AND REVIEW PROCESSES FOR SICAP

\begin{tabular}{|l|c|}
\hline Level of involvement & $\%$ \\
\hline Somewhat involved & 3 \\
\hline Very involved & 5 \\
\hline Extremely involved & 2 \\
\hline Total & 10 \\
\hline
\end{tabular}

\begin{abstract}
A1.10 Social enterprises
Seven per cent of LCGs assisted social enterprises, just 1 per cent of LCGs received funding to assist social enterprises while a total of seven new social enterprises were established. There was quite a geographic spread with new social enterprises established in Cork, Dublin, Galway, Kerry, Mayo and Tipperary.
\end{abstract}

TABLE A1.16 LCGS ASSISTING AND ESTABLISHING SOCIAL ENTERPRISES

\begin{tabular}{|l|c|c|}
\hline & $\mathbf{N}$ & $\%$ \\
\hline LCGs that assisted social enterprises & 220 & 7.1 \\
\hline LCGs that received SICAP funding to assist social enterprises & 31 & 1 \\
\hline LCGs that established new social enterprises & 7 & 0.2 \\
\hline Total LCGs & 3,076 \\
\hline
\end{tabular}

\title{
A2 PROPOSED INDICATORS FOR MEASURING COMMUNITY DEVELOPMENT FROM CONSULTATION WORKSHOPS
}

- Participation/Engagement: The number of individuals who show up/participate/are members; absolute numbers or measure as a percentage of community; duration and frequency of attendance; number who don't participate can be used also; number of new members; share of core group of members, i.e. same people versus new members; number of visitors; number on waiting list; full capacity.

- Interventions: Measure the number and intensity of interventions.

- Networking/Collaboration: Number of new networks formed; collaboration/links with other groups; how many other groups know about this group; how many people know about it; how many have access; collaboration with other areas (including more affluent areas); networking to share best practice/talents; measure collaboration locally (groups/organisations), regionally (PIs), nationally (PIs and others) and internationally; connections on both practical and strategic levels; movement from/between groups, e.g. flower-arranging group may lead some individuals to move to refugee group.

- Monetary Contribution: Being financially viable; voluntary monetary contributions. 
- Funding: Use funding applications/level of funding coming into an area; supports from public bodies/LDCs, etc.; amount of advocacy and lobbying.

- Voluntary Contribution: The number of volunteers; measure contribution of voluntary sector/Community Employment (CE)/Tús contributions; drawing on community - both people and time.

- Community Development Tape Measure: Measurement should be related to the purpose of the groups; make a community plan and go back and evaluate it - if people are happy with it then that is a measurement; community tool box - measure well-being, education, etc. and adapt to Ireland; if each group has its own measurement tool then have very definite measurement along the way - where were you last year, where were you this year; outcomes/Impacts - analyse feedback and ask what's the point and what has changed; measures need to be sufficiently nuanced/flexible to capture the wide variety of the different groups with different purposes from well-being focus to single activity - different time frames; focus on the change that the group wanted to happen and the process involved; taking a group and where they are at and some might never progress but they are still functioning and still meeting; quarterly milestones in Local and Community Development Programme (LCDP) - periodic measurements should be used; use narrative reports to show group's impact; categorise community plan under health, education, enterprise and happiness of community with outcomes; have information on goal/plan from Pobal at the start, then ask what is needed; should be a person-centred approach where people are assessed at the very beginning and progressed as they go through four stages of the index and you see where they are at and give them the same questions.

- Surveys: Should be done at group session anonymously, asking did you enjoy event, would you return, what would you change what did you like about the programme and what did you achieve?; standard community survey done once per year; questionnaire to all LCGs ask what has the group achieved; survey at various stages throughout the programme; fill out a form and ask is there an improvement in the following areas: $x, y$, $z$, then yes/no is a measurement; verbal feedback; Richter scale - self assessment is used by them for employment - scored on 1 to 10; Quantify feelings - scale of one to ten, how satisfied are you with your group.

- Case Studies, Evaluations and/or Personal Statements: Collect more qualitative data using open question rather than tick box; movies, pictures, stories are all very effective at pre-development level; anecdotal reports are valid way of measuring quality as is relevant information from stakeholders; impact on individuals using one to one evaluation which is not invasive; have two sets of questions: one for the groups and one for the individuals.

- Social Media/Technology: Use Facebook to measure number of Likes and/or Hits for a group event; Also can use technology for surveys (survey monkey), polls and videos; The sense maker app created by David Snowden can be used to measure quality with the benefit that the person themselves can answer it rather than the organisation; Get community members to click 'Sad' and 'happy' faces like what is available at the airport. 
- National Data: Census used to get a true picture of what is actually happening; Go back to census and check the demographics that are available which could be used; There is a need to look at the use of small area as a capture of the activities of community workers; Reduced inequality/income; Perceptions outside the community; Look at house prices and by how quick a house sells; percentage on electoral votes / those on register; collating available data across groups/agencies to capture the bigger picture.

- Progression: There are objective measures out there that could be used such as progression to a formal structure, constitution, procedures, governance code, accessing funding, and development of leaders.

- Baseline Data: Baseline data are a necessity. Use them to measure change. Measure against the definition of community development.

- Visual Evidence: This can be used as evidence-based proof of project - e.g. building a playground.

- Sustainability: Stability and sustainability of group; how many years ago the group started; rejuvenation for groups that have been around a long time; level of dedication and commitment.

- Well-being, Health, Happiness, Sense of Community, Equality and Inclusion: Social interactions (more contacts); more confidence; less isolation; better mental health; sense of purpose; feeling in control of your own destiny; feeling empowered; integrating in the community; subjective individual change - how satisfied or proud of living in the area?; do young people want to stay in the area; evaluation of the community workers themselves and all LCG participants regarding their health, happiness, employability, education (by their contribution); sense of personal and community power and agency to effect change; education, employment status, trust, hitting services which government doesn't know about; first impressions of group members, did they feel welcome, belonging and support?

- Social Change: The group should be measured in terms of the social change it is effecting and this could be done in a standardised framework.

- Demographics: The age of the new members or existing members; number who are young members; number of marginalised people brought back in; number of participants who are not in lifelong learning or employment; those who are active (not economically) but connected to community.

- Demand: Outcomes can be measured by demand for groups/events; the number of promotional activities.

- Talk to the Participants: send observers to communities to get more of a feel for what is happening on the ground; indicators need to reflect the work taking place on the ground with groups at the different stages.

- Knowledge: Need to reflect new and improved knowledge within the group; measure awareness of governance and mission and objectives; is there a planned structure in place? 
- Strategic Involvement: Whether the group has a voice; participated in a PPN.

- Skills: The number of new skills - physical and mental -- that were acquired; improved communication skills.

- Events: The number of activities or events such as day trips, e.g. members of Men's Shed go to ploughing championships; number represented at workshops, training courses, etc.

- Services: The number of services available, e.g. bus service.

- Spill-Over Effects: How to measure community participation as prevention of future health problems; for example, joining the Men's Shed stopped health deteriorating down the line; ripple effect of helping an individual as this may lead to a benefit for those around them which is very difficult to measure.

- Logic Model:

- Inputs - members, familiarity, relationships and trust, time commitment, space and premises to connect (schools, churches, community facilities).

- Activities - roles, more democratic structure, learning to resolve difficulties, common goals/work plan, structure, overcoming complacency.

- Outputs - meeting your goals, change plans if needed, footfall engagement, gather feedback.

- Other:

- Poor outcomes and lack of cohesion within the group.

- If the group changed status and moved to a charity, limited company, etc.

- The amount of local administration conducted by the group.

- Have a national programme with four or five key areas, which groups all work on.

- The group members' emotional reaction and behaviour throughout the programme.

\section{A3 SUMMARIES OF THE INDIVIDUAL WORKSHOPS BY THEMES}

\section{Workshop 1 - LCG Members}

A. What is the most appropriate overarching approach to measuring community development, in the context of SICAP?

- There is a need for some form of measurement of the work, a need for accountability.

- Need for national and local profiles but also to recognise that one tool does not fit all just because it works in Limerick does not mean it will work in Galway.

- Measure community development work (CDW) - who, where, when, and how often is captured in IRIS. 
- Measure impact of participation in group. Things that are difficult to measure - sense of community health and well-being.

- Case studies/personal statements.

- Interviews combine questions and free spaces, answers recorded.

- Focus groups useful only if questions are understandable - not too theoretical or abstract.

- How much of community workers' (CW) time is spent on admin versus CDW?

- Not everyone wants to answer, can answer, or is comfortable with questionnaires.

- Who designs the questions - are they familiar with CDW?

- What do you want to know?

- Results should be independent and information should be shared back with the group.

- One measurement tool doesn't fit all.

B. Which indicators most effectively reflect changes in community development and the capacity of communities to effect change?

- Verbal feedback.

- Course evaluation - gardening had course evaluation, which helped.

- New improved knowledge.

- Networking.

- Links to other groups (this can be a positive/negative outcome). Percentage outside the community who came in made the group feel not exclusive.

- Engagement was the main indicator - turning up/participating/new member.

- Passing on knowledge. New members - waiting list.

- Percentage of community - participation rate.

- Percentage on electoral register.

- Non-participation can also be an indicator.

- Strong leaders and followers.

- Number of volunteers.

- New members/visitors.

- Critical mass. 
- Full capacity - tangible measure.

- Collaboration/links to other groups.

- Monetary contribution.

- Inclusive for all age groups.

- Some groups said community development meant change but others suggest that stability and sustainability is a better outcome.

- Perspective is important - same outcome perceived differently.

- Attend course then join group.

- Duration and frequency of attendance.

- Dedication and commitment.

- Skills building. Learning - physical and mental.

- Conflict resolution.

- Poor outcomes and lack of cohesion.

- Being financially viable - maybe voluntary contributions.

- Core group of members - same people versus new members.

- First impressions - welcome and support, feel welcome, belonging.

- Main things - engagement, turning up, attendance, numbers a good indicator for some but not others, financial contribution a good measurement.

C. In terms of the community group progression matrix, to what extent is progression the norm, and is progression along this matrix a true reflection of capacity-building at a community level?

- Groups usually progress but not along the full matrix.

- This is no reflection of whether the group progressed.

- Better to have circular matrix rather than linear matrix. It depends on the aim, vision and ethos of the group.

- Circular matrix more reflective of reality - two steps forward, one step back.

- Groups do need to progress but this could be measured in terms of 'learning'. As long as they continue to learn, this is success/progression.

- 'Learning' should be happening both within and outside of group. 
- Other progress named in terms of sustainability of group, increased numbers, flexible nature of group, responding to new demands.

- Might be affecting policy at national level but not achieving what you set out to do.

- Need to have a clear vision and ethos and carefully structured plan. Open participation essential. How the group is set up at the start is very important to its eventual progression. Open communication. Constantly refer back to what they were trying to achieve in the first place.

- Communication important.

- Groups must continue to achieve change. Individuals must gain something from being a group member.

- Different measurement tools for Issue-based groups versus 'hobby groups' although one may merge in to another, e.g. a knitting group could influence policy.

- Difference between groups that are more project-based and those that do the same thing week in, week out.

D. How can we improve the existing approach to data collection in order to more accurately reflect changes in community development in areas supported by SICAP?

- Some clarity on where the data are going so people know.

- Expectations - disappointment in no follow-through. Ask/motivate on paper.

- One-on-one conversation.

- Get people's views through surveys, forms. First meeting.

- Use numbers who have access to group, e.g. community space.

- Questions are over-complicated - not sure what they are looking for.

- Literacy an issue, fear of being found out, won't turn up. No sensitive data, e.g. council house. No forms before action. Do people filling forms know the purpose?

- Assist or converse.

- Organiser seen as vested interest.

- Be specific on data - not getting to policy matters.

- Form has very small boxes, too difficult, not sure what data collection wanted. Lack of knowledge of form's use.

- LCG form filled by one person not shared.

- Different LCGs require different levels of sensitivity, e.g. gardening vs adult learning. 
- Standard community interview to gather unseen work that is not gathered - maybe stories, video, soundbites.

- Sustained numbers over time.

- Not visible, network support unseen.

- Show how data are used by Pobal. Are they necessary? Show that data are helping, then may be more inclined to answer the questions.

- Add LGBT to target groups.

- Group finished due to no purpose or because group succeeds?

- How many other groups know about this group; how many people know about it? How many have access? How many people in group?

- How many promotional activities?

- Could be anyone signing forms.

- Information should be shared to save time - join up .

- Matrix does not measure progression - need more stories and anecdotal evidence.

- Surveys should be done at group session anonymously - did you enjoy event? Would you return? What would you change?

- Standard community survey - once per year. What are your interests?

- Potentially more than one signature.

- Forms not indicating on Census level 2 up - disregarded.

- Community worker to assist in community group survey - not enough information on what question means.

- Home-life question unnecessary and dangerous.

- Need to know how secure data are - not very clear.

- Trust.

- Interviews with group, how many people have access to the group, e.g. walk around gardens.

- Forms don't reflect work of group.

- Forms needed to reflect different groups.

- Essential for funding, forms are important.

- Put aims in note section. 
- Overall there is agreement that forms are needed but just require more clarity.

\section{Workshop 2 - LCG Members}

A. What is the most appropriate overarching approach to measuring community development, in the context of SICAP?

- Quantitative measures are not a true reflection. Need qualitative measures.

- Not as effective to measure at a broad level as at a local level.

- Census used to get a true picture of what is actually happening.

- Tick box means individual measures are lost.

- Not measuring community development, more SICAP value for money rather than change and what is really happening on the ground.

- Quantity seems more important to SICAP than quality.

- Set targets and measure around lifelong learning.

- Distribute newsletter of what's available in the community.

- Use case studies and collect more qualitative data, open question rather than tick box.

- Send observers to communities to get more of a feel for what is happening on the ground.

- Administrative burden of staff reporting back and ticking boxes.

- Mapping, people don't know or have any connection with anything else that is going on in the area - need better profiling, better benchmarking as to what is going in. Sense that starting off at day 1 like nothing has ever happened.

B. Which indicators most effectively reflect changes in community development and the capacity of communities to effect change?

- Reduced inequality/increased income.

- Collating available data across groups/agencies to capture the bigger picture.

- Level of funding coming into an area.

- How many people are participating and volunteering?

- Some groups are kind of closed shops - same faces. Need to make participation broader.

- Advocacy and lobbying.

- Who to talk to about decisions. 
- Collaboration between groups - funding creates competition?

- Sustainability - important not to be dependent on outside agencies like SICAP -if programme is cut then this will stop - be more community-based.

- Structured planning and evaluation.

- Collaboration with other areas (including more affluent areas).

- Subjective individual change - how satisfied/proud of living in the area - do young people want to stay in the area?

- Perceptions outside the community. Look at house prices perhaps.

- Measure people not in lifelong learning or employment, those who are active (not economically) but connected to community.

- Sense of personal and community power and agency to effect change.

- Pobal definition of community development relates more to service provision than to community development.

- Circular matrix - people get involved then drop off, but then come back.

- Group formation - minimum of two to three people who have identified a gap and some shared goals - willing to learn from other groups/programmes.

- Capacity-building - gathering resources, money (fundraising) and human (volunteering), identify what skills you need (grant applications). Also structure of the committee, roles, meeting, minutes.

- Collective action - a lot of time one person doing it, so need to delegate and share the burden. Designing and implementing solutions; overcoming barriers from bureaucracy (difficulty getting insurance). Make sure that other bodies don't take over the group and that communities maintain ownership.

- Strategic involvement - identify decision-makers, make submissions, link with similar groups (national/international) and participate in structures (PPN). Try not get cynical and do not take no for an answer; inspire and support other groups -- the young plus emerging community leaders (mainly older people involved thus far).

- Logic model.

- Inputs - members, familiarity, relationships and trust, time commitment, space and premises to connect (schools, churches, community facilities).

- Activities - roles, more democratic structure, learning to resolve difficulties, common goals/work plan, structure overcoming complacency.

- Outputs - meeting your goals, change plans if needed, footfall engagement, gather feedback. 
- Outcomes/Impacts - analyse feedback (qualitative), deal with cliques (involve new blood), what's the point? What has changed? Show your impact.

C. In terms of the community group progression matrix, to what extent is progression the norm and is progression along this matrix a true reflection of capacity-building at a community level?

- Stages 1 and 2 are OK.

- Stage 3 is goal that people strive for; it helps with isolation, social inclusion; people do not always get to Stage 3 .

- Balance of all three goals needs to be maintained.

- Stage 4 is not something a knitting group would strive towards, but maybe a community centre would. Important that the correct skill set is there.

- In some cases influence national framework but not known.

- Fear of Stage 4-you bring yourself out of the community. Is that what you want?

- Volunteering burdensome - Garda vetting and checks.

D. How can we improve the existing approach to data collection in order to more accurately reflect changes in community development in areas supported by SICAP?

- Lack of familiarity about SICAP in general, particularly community development and what data are currently being gathered.

- Communication and awareness of SICAP. Language of SICAP should be more accessible if want to increase awareness.

- The intimacy of questions is unnecessary, will discourage people from attending; people don't want to fill out these forms.

- Highlighting positivity of SICAP, for instance in local newspaper.

- Lots of statutory organisations. Community development means different things to different funders - have a common framework of what community development entails, indicators of when it is effective, e.g. Community work Ireland; Better Outcomes, Brighter Futures.

- Matrix is too rigid and formulaic.

- A national community development (CD) framework is needed similar to Healthy Ireland.

- Need more qualitative data -- what are the good things that make you want to stay and live in your area - qualitative things being captured in IRIS?

- Overthinking. Perhaps it is more straightforward than we thought. 


\section{Workshop 3 - LCG Members}

A. What is the most appropriate overarching approach to measuring community development, in the context of SICAP?

- Every group said it should indeed be measured.

- Measuring numbers, turn up, quantitative is fine.

- Use social media - number of likes, hits, surveys, polls and videos easy to measure.

- Go back to Census and check the available demographics that could be used.

- Make a community plan and go back and evaluate it - if people are happy with it, then that is a measurement.

- Categorise community plan under (a) health, (b) education, (c) enterprise and (d) happiness of community with outcomes.

- How do you measure cost to state of what voluntary sector does?

- Measure by house prices and by how quickly a house sells.

- Corporate approach to CD is flawed as doesn't measure the voluntary contribution.

- Methods for measuring quality - SenseMaker app (creator of app: David Snowden; idea: the person themselves can answer it rather than the organisation).

- Sad and happy faces like in airport/Lidl.

- How do we know the value of today's workshop?

- Keep things simple - health and happiness.

- A change of ethos from a corporate approach to a community approach led by community and local development - start from the ground up.

- LCGs go to ESRI/Pobal on their terms.

- How do we know the value of today's workshop?

- Feedback from staff is valuable - no existing process for measuring contribution of voluntary sector/CE/Tús contributions.

- Evaluation of the community workers themselves and all LCG participants regarding their health, happiness, employability, education (by their contribution).

- Happiness itself is an indicator.

- Fill out a form - is there an improvement in the following areas: $x, y, z$ ? Then yes/no is a measurement. 
- How do you measure more contacts, more confidence, improved communication skills, sense of purpose, feeling in control of your own destiny, feeling empowered, integrating in the community?

- Need a community development tape measure.

- Outcomes can be measured by demand for groups/events.

- Anecdotal reports are a valid way of measuring quality as they contain relevant information from stakeholders.

- There is no evaluation of the true quality of $C D$, e.g. social interaction, share talents, supporting other LCGs, environment.

- Working with other groups, marginalised people brought back in.

- Community Tool Box - measure well-being, education, etc.; adapt to Ireland.

- How to measure community participation as prevention of future health problems - for example, joining the Men's Shed stopped health deteriorating down the line.

- Big disconnect between people at the top and those on the ground.

- Powers that be should trust staff working on their ground and ask for their feedback.

- More consultation with service users.

- Questionnaire to all LCGs - what has the group achieved?

- Keep everything simple - newsletter, social media, word of mouth, encouraging people to participate.

B. Which indicators most effectively reflect changes in community development and the capacity of communities to effect change?

Pre-development group formation

- Go back to local development company (LDC) offices on the ground.

- Use social media - Facebook, Twitter, etc.

- Census - does it say if we are a member of a community organisation? (Census 2011 does.)

- Local surveys at pre-development stage.

- Broaden the census - how do you measure success/failure?

- Need to measure: health/education/employment/voluntary services/ savings community groups provide money for education, food, shelter, fuel, mental health. 
- Key is to keep everything simple. Newsletters/ individual assessments /measure where you are at - same questions asked at stage 1 . Satisfaction index $->$ how do you represent this in a monetary manner?

Capacity-building and empowerment

- Indicators of development - status moved to a charity, limited company, etc.

- Demographics of new members, young members.

- New members, young members, get the youth involved, the Gaisce awards.

\section{Collective action}

- Drawing supports from public bodies/local development companies (LDCs) etc.

- Survey at various stages throughout the programme.

- Drawing on community - people and time - how do you value that?

- Visual evidence-based proof of project, e.g. building a playground.

- Local administration.

- Sharing best practices.

- Strategic Involvement.

- Representation at workshops - people were happy to be at workshops but language is too convoluted.

- Men's Shed got to go to ploughing championships.

- Funding applications could be used.

- Health, education, employment status, hitting services that government doesn't know about.

- Measure of time involved, not just numbers.

- Being involved in PPN. Have a voice.

- Should be a person-centred approach where people are assessed at the very beginning and progressed as they go through four stages of the index, so you see where they are at and give them the same questions.

- Capacity for an incentive structure to allow funds to increase as the LCGs progress?

- National programme so that across the country, four or five key aspects every area works on.

- Have information on goal/plan from Pobal at the start then ask what is needed?

- What is needed is more important that what is wanted. 
- Emotional reaction/skills/behaviour throughout the programme.

- What did you like about the programme and what did you achieve?

- Rather than Pobal giving money if we achieve each stage, they say what we are going to do and then we get the money.

C. In terms of the community group progression matrix, to what extent is progression the norm and is progression along this matrix a true reflection of capacity-building at a community level?

- How do you include everyone in your community - parish newsletters, get groups not usually involved interested, how to get a plan to target everyone?

- Planning - what are the objectives?

- Amount of admin for small group versus larger group. Puts many volunteers off joining groups.

- Why are people dropping out of groups?

- What external supports are there out there for groups? How they do know or connect them?

- Community learning from other groups that are doing really well.

- Finding the right role for the right person - supported by an outside body.

- Evaluation of community plan, community evaluation and networking.

- Quantifying communication versus people reached. Can you put a number on it? If sent out letters, how many people came back?

- Action versus reward for the community/community group.

- Every project has a beginning, middle and end.

- The matrix is a good way to measure but it is monitoring and measuring versus selfassessment.

- Stage 1: ideal $\rightarrow$ public meeting for group formation. Success measured by number attending. Accountability through meetings. Social media - target everyone. Plan structure - what outcomes?

- Problem - skill set of the founders; same people doing everything. Some groups might exist permanently at Stage 1, so how do we measure progression? Governance risk versus governance.

- How do you sustain this stage? Do you measure drop-out? 
- Common goal needed. Willingness for communities to volunteer, governance should be only part of it - open door policy.

- Stage 2: progression $\rightarrow$ need training, governance, committee rotation on boards, support and training around legislation. Mechanism to help group have engagement. Are there supports for smaller groups to progress? Why do people drop out? Monitor dropouts. Outside facilitator for groups to help everyone find the right role. Learning from best practice. External supports. Voluntary activities saturated with events.

- Stage 3: plan reaching goal - keep it simple. What have you achieved? Committee attendance. Projects completed. Community collaboration and networking. Quantifying communication and people reached - feedback. Younger people. Monitor mentoring assisting.

- Stage 4: Not every group needs to progress. Do groups want to advance?

- Matrix is a good way to measure progression once have a strong group but monitoring versus mentoring versus measuring self-assessment for group.

D. How can we improve the existing approach to data collection in order to more accurately reflect changes in community development in areas supported by SICAP?

- Simplification and language of the indicators, e.g. deprivation.

- Who is Pobal to Tidy Towns?

- People don't feel like they are living in community development.

- If no volunteers then there would be no community development.

- It is not that community development is going away but that groups are struggling because it is just too cumbersome to bother to apply for grants - stand outside the church instead.

- Good to meet up, as you can get a sense of if there is something up with the person and can then get community workers to give them a call - can't measure that.

- Actuals and targets - actuals are what is happening within the community; should become the actual targets rather than making actuals fit the targets.

- Information is being lost amid all the information. A lot is recorded, but what happens?

- What happens in one community may not work in one next door.

- Community strategies rather than national/regional strategies.

- Animation - coming out and listening to communities, and create a plan for the community after sitting in 'cold country halls on dark evenings'.

- How to structure the task, who is going to do $X$ and $Y$. 
- Engagement challenge is measurable.

- Language of the programme is too complex.

- Feel more focus on activation rather than community group/social inclusion.

- Relevance of indicators as they stand: targets versus what's needed.

- Past achievements.

- Looking at existing statistics - innovating new option.

- Tracking socio-economic plan.

\section{Workshop 4 - LCG Members}

A. What is the most appropriate overarching approach to measuring community development, in the context of SICAP?

- Easier to measure locally in terms of SICAP than to measure the broader development within the community.

- Do the community groups have all the information? How they can impact the community?

- Are community groups working together? Should SICAP be facilitating this? If many are working together then this will affect the broader impact of the community.

- Change in attitudes within the group with pre-evaluation and post-evaluation.

- Credibility of the evaluation - they tick a box, someone writes a report and no one ever reads it. More likely to give the feedback if there is more - in order to get quality, accurate data the community needs to trust that it isn't a 'box-ticking' exercise.

- Short-term measurements easier than long-term.

- One size does not fit all - there is a huge difference between the groups.

- Doing it at a broader level is going to be less accurate than doing it at a local level.

- Some outcomes may be amazing for some groups but not for other groups - only the group knows what is big for them.

- Quantify feelings - on a scale of 1 to 10 , how satisfied are you with your group?

- Have two sets of questions: one for the groups and one for the individuals. 
B. Which indicators most effectively reflect changes in community development and the capacity of communities to effect change?

- Community groups are not good at evaluating their own progress. They will set out their objectives and goals and only review them when doing a funding application.

- Numbers participating, knowledge within the group, sustainability, connection with other groups within the community. Connections on both practical and strategic levels.

- Example from group: joined a toddler group, then saw gaps in community and so set up facilities, drama group, all done through playschool and social media - got feedback from social media asking do you agree we need this.

- The amount of administration and paperwork required for government survey is just too burdensome and people walk away.

- Number of participants doesn't reflect the impact, e.g. impact of five/six might be more important than group with 60 people.

- One size does not fit all - best indicator is some sort of self-assessment - need some sort of measuring tool.

- Impact on individuals cannot be done numerically - must be one-to-one evaluation - not invasive.

- If each group has its own measurement tool then have very definite measurement along the way - where were you last year, where were you this year?

- Rickter Scale - self-assessment is used by them for seeking employment - scored on 1 to 10.

- Ripple effect of helping an individual, benefit of helping one benefits those around them, which is very difficult to measure.

- Survey Monkey.

- Strength of group measured by - numbers, how long, continuity, rejuvenation for groups who have been around a long time.

- Can have a group where the church, post office, etc. is closed but the community group got together and got funds to build a vocational school, and this is a bigger deal than in an affluent area.

- Need more support on the ground from community workers, maybe to groups on where they are going right. Bus service makes a huge difference to people buying a house in an area.

- Broad measure, e.g. population doesn't isolate SICAP.

- Measuring value for money is difficult, e.g. number of sewing machines bought.

- Provide guidelines for self-assessment. 
- Measure awareness of governance and mission and objectives. Is there a planned structure in place?

C. In terms of the community group progression matrix, to what extent is progression the norm and is progression along this matrix a true reflection of capacity-building at a community level?

- Specific to programme. Individuals within a community group may progress themselves - that is not recognised fully.

- Progression is being measured in the wrong way.

- The progression should be the other way around and not forced on groups - the groups should decide themselves.

- Focus should not be on value for money, more on individual progression.

- Natural progression.

- Capacity and empowerment are ongoing, so more cyclical than linear as at every stage they are ongoing.

- The positive impact on individuals is not being measured at all.

- No way of capturing social inclusion. Rural transport service which can have a positive effect on all communities is not captured. Should include the subtle ways social inclusion works.

- Unrealistic understanding of how social inclusion works.

- Not all groups progress in a linear way.

- The matrix does have merit as it gives groups a focus.

- A lot of groups don't want to get to the last stage.

- Pobal has defined social inclusion too narrowly.

D. How can we improve the existing approach to data collection in order to more accurately reflect changes in community development in areas supported by SICAP?

- Make data collection less invasive, and needs to be more relevant to the programme undertaken.

- If they don't want to fill out the forms then they can't work with them, which is not socially inclusive (i.e. the data themselves are creating barriers).

- Asked for invasive information the first time you meet, and no time to build up a rapport. 
- The right information is not being collected. For asylum seekers, what you can do for them is not being collected at all so there is very little they can get from the forms.

- If the questions are creating exclusion then it is absolutely terrible. Very crude questions.

- Terminology/language in the forms makes it harder for people with poor education or literacy issues or even anyone to understand, which creates a barrier - keep it simple.

- There is overlap as they are the same questions for other programmes - and then individuals want to know why they both need the information.

- Too many layers before the forms coming out and getting to voluntary groups. Impossible for voluntary groups to fill out as don't have the expertise or time.

- Not worth the time. Committees decreasing due to the new governance structures that they don't want to be involved in.

- If only two people on the PPN, how active are they in that group?

- Data protection, insurance, responsibility, use of CCTV camera.

- Disconnect between what is being collected and the people who need it.

- Ensure communication that the information is actually collected.

\section{Workshop 5 - Local Community Workers}

A. What is the most appropriate overarching approach to measuring community development, in the context of SICAP?

- Combination of broad measures and community group SICAP supports - concern regarding correlation and causation.

- Measure qualitative outcomes and progress.

- Measure interventions - number and intensity.

- Baseline data are a necessity.

- Expertise is on the ground already through the workers and partnerships.

- Measure of intensity, e.g. if have to meet a group 20 times. Need to measure qualitative outcomes and progress.

- Look at 'Health Impact Assessment' - Limerick regeneration project - takes health and well-being into account.

- Look at collective determinants, measure at community group level, e.g. well-being. 
- Focus on the change that the group wanted to happen and the process involved; need a measurement tool to capture that. Taking a group and where they are at, and sometimes they might never progress but they are still functioning and still meeting.

- Community development definition - measure the achievement of social change by focusing on the measurement of the change you want to happen and the process involved.

- It is not optimal for the LCG to put the aim of the group in IRIS, as not all groups have clear aims and objectives.

- Core focus of the group. Help clarify. For example, for Roma men focus is meet regularly.

B. Which indicators most effectively reflect changes in community development and the capacity of communities to effect change?

- They should be qualitative in nature; at the moment they are overly quantitative.

- Quarterly milestones in LCDP - periodic measurements should be used. Emphasis on narrative reports.

- Reintroduce trust and respect for professionalism.

- Indicators need to reflect the work taking place on the ground with groups at the different stages.

- Work with LCGs not recorded very well in IRIS. It needs more time, and frontline staff should be consulted.

- If you want to record these measures you need to give it more time.

- Recommend more recognition of collaboration. It's happening but is not promoted.

- Should try to measure collaboration: locally (groups/organisations), regionally (PIs), nationally (PIs and others) and internationally.

- Important to have networking to share best practice.

- It's very important to build trust.

- Pressure among Pls as could be just one PI - constantly trying to reach targets.

- Flower-arranging - reduction of isolation, better mental health, make a significant social impact that goes beyond. Flower-arranging group may lead some individuals to move to refugee group. Movement from groups.

C. In terms of the community group progression matrix, to what extent is progression the norm and is progression along this matrix a true reflection of capacity-building at a community level? 
- Pre-development stage -- progression is determined by the group.

- The matrix is not a true reflection of true development. No recognition of work involved, complexities that present.

- Matrix linear but reality is chaotic and challenging, which is not included.

- Cyclical option might be better.

- Stages are interchangeable.

- People are afraid to report moving back from C to A - SICAP is causing this.

- Stage 4 is a myth as if get to level of PPN or LCDC, these are hostile places for community reps.

- The fault is the department. Need to make institutional and attitudinal changes at that level. SICAP people are treading water.

- There are meetings about meetings about meetings.

- They want sustainability for their group - that's progression.

- Progression matrix should be determined by the group. Classification of groups. It only fits some groups. Refugee group could require significant impact whereas knitting group maybe only two interventions

- Capacity building can also be accomplished at Stage 4 .

D. How can we improve the existing approach to data collection in order to more accurately reflect changes in community development in areas supported by SICAP?

- Optimal ignorance.

- Refine and reduce amount of information. It's a deterrent for a lot of groups.

- Use of narrative and milestones quarterly report to reflect on the work on the ground.

- Census data - links to section A (issues and challenges noted).

- Need to collaborate with frontline staff. Work together for solutions.

- Request more active role with Irish Local Development Network (ILDN).

- Ask for time for staff to meet, voice concerns and work on solutions.

- ILDN and Community Work Ireland should be invited.

- It's been too turbulent; each wave changes (even the logos). Used to be able to get grant aid; for example, get $€ 200$ to get groups off the ground.

- Too many changes not helpful for community group development. 


\section{Workshop 6 - Local Community Workers and Stakeholders}

A. What is the most appropriate overarching approach to measuring community development, in the context of SICAP?

- There are a number of definitional approaches to community development.

- There are differences in how the definition is interpreted and operationalised by LDCs.

- Community development definition given by SICAP. Does everyone agree with it? It goes back to the local development plan (LDP) 1994/1999 (Also a Combat Poverty agency definition from 2000).

- It is very complex and rich. Does everyone understand it? And apply it in the same way?

- Need to be operating on the all-Ireland community standards approach as it is objective and easy to interpret.

- Practice versus theory.

- Staffing issues with some LDCs.

- It's not feasible to attribute SICAP funding to change that occurs on the group.

- Capacity needs to be built within LDC.

- Public sector duty. Human rights and equality community legislation.

- SICAP enables other funding streams

- LDCs predate SICAP.

- Is it realistic to measure and evaluate community development as the overall government expenditure is so low in this area?

- What has SICAP done for the following types of measure: equality, inclusion, participation?

- The RAPID (Revitalising Areas by Planning, Investment and Development) model highlighted as a successful model.

- In terms of measuring change, there is actually very little movement in the deprivation levels of communities over time. Areas considered affluent/disadvantaged 20 years ago are still the same; some exceptions in inner-city Dublin.

- Does community development just take place under Goal 1? There are also individuallevel interventions under Goals 2 and 3 that impact community development work on the ground.

- Focusing on small areas in terms of a broad approach would not be the best way to measure the impact of SICAP.

- Better to focus on measures that are aligned to community development principles. 
- There is a need to look at the use of small areas to capture the activities of community workers.

- Tracking social change.

- Equality/inclusion/participation.

- SICAP doesn't operate in isolation. Referrals. Pathways to other programmes. Also have Tús/LEADER/Local Employment Service (LES).

- Actions under thematic: horizontal themes. Need to focus on actions under thematic headings; some qualitative information currently collected but not really reflected within the current assessment framework.

- Horizontal themes. Equality, gender, poverty proofing.

- Extrapolate good practice from end-of-year reports. Need to use the annual reports to develop a proper narrative of what is happening with regard to community development on the ground. A body such as the ESRI could potentially analyse these reports to provide a unified view of changes that are occurring in the areas of $C D$ as a consequence of SICAP funding.

- Need to upskill workers in LCDCs?

- Measuring the change within the overall community.

- Cannot put a line around activities happening in a community (centre) as people attend courses from outside 'disadvantaged areas'.

- What is the appetite for effective measurement of $C D$ ?

- Years ago LDCs commissioned thematic research. They had their own budget for research.

B. Which indicators most effectively reflect changes in community development and the capacity of communities to effect change?

- No one is satisfied that the current metrics are effective, particularly in capturing the intensity of interventions.

- Used to be called SIAP; community was only brought in as an aside.

- Ambiguity around term 'community group'. How do you identify the group itself?

- The measures are not being effectively captured. All the pre-development work.

- Progression framework reflects the needs of funders more than those of groups.

- Groups are different, single-focused, some with no interest in progressing, one size doesn't fit all. 
- Linear framework does not take account of the organic or cyclical nature of community group development.

- No point trying to fit groups into a framework.

- Any measurement framework needs to reflect the different nature of groups and the level of intensity of interventions to get them up and running.

- Again the use of case studies and qualitative information is important to reflect change, particularly at the development level - current focus is on IRIS completely.

- Group should be measured in terms of the social change it is effecting and this could be done in a standardised framework.

- SICAP starts better with individuals rather than community groups.

- Any measures need to be sufficiently nuanced/flexible to capture the wide variety of the groups, with different purposes - from well-being focus to single activity - and different time frames.

- Indicators need to reflect the time investment.

- There are objective measures out there that could be used, such as progression to a formal structure, constitution, procedures, governance code, accessing funding, and development of leaders.

- Case studies, movies, pictures, stories are all very effective at pre-development level.

- Staffs haven't got the training to respond to the measure. Pobal needs to resource groups through training/networking.

- Need to be measured knowing/against the definition of CD.

- Logic model is useful.

- How to measure a lot of pre-development work - go and actually talk to the participants.

- Measurement should be related to the purpose of the groups. Greater well-being.

- Measure social change at each stage. Ability to measure variance.

C. In terms of the community group progression matrix, to what extent is progression the norm and is progression along this matrix a true reflection of capacity-building at a community level?

- Three of the four groups felt that the matrix does not measure progression.

- Potentially useful if underpinned by CD principles.

- Linear nature of the matrix is not helpful - people and capacity within groups come and go. 
- Different views of capacity-building, is it about making high-level societal changes or collective action?

- Can we capture public sector duty into a matrix designed to measure CD?

- How do we get the doers of this world to understand the value of CD?

- Where is the oversight role to ensure that the CD definition is being followed, the AlIreland principles are being put into effect? Completely missing from the matrix.

- Staff understanding of what CD is.

- Can a matrix actually reflect the way in which community workers are responding to the needs of communities?

- Need to establish baseline and progress being made against the baseline, particularly given that the baseline will differ from group to group.

- People come and go and some changes to key personnel, then it falls apart.

- Ensure that real social change is being sought and striven for.

- How do you go from the individual to the group stage?

- Cyclical.

- The governance code.

- A greater appreciation is needed for CD.

- SICAP does not stand alone; it is a critical element of core funding but does not provide all the supports that are necessary to get the work done.

- Collaboration, integration.

- Who provides the national oversight to ensure that this work is actually being done?

- Whose needs are really being met - who is articulating those needs and how does a matrix like this really capture this?

- Need baselines and measure progress against these for each group/area of work.

- Rationale can be provided if things don't work out as initially planned.

- PIs absorbing funder's language and complicating the work unnecessarily.

- Some groups remaining at a stage is progress.

- Critical issue regarding what the LCG is supposed to do - core mission regularly revisited and confirmed.

- Role of SICAP implementers is to move formal structures into place.

- LCDCs need an understanding of all of this and how it should inform their work. 
- SICAP should ensure that the CD definition is underpinning this matrix.

- National oversight critical. Lack of capacity on LCDCs to dictate to SICAP implementers.

- Men's Shed groups may not progress as such, though individuals within the group may progress.

- Pressure to get individuals into representative bodies, e.g. PPNs.

- Local CD course being run to meet local rep needs rather than what people feel needs to happen.

- Work can be controversial as groups developing work and then challenging local authority if they are not delivering as they should.

- Partnerships now implementers and value of partnership lost.

- Challenge of managing work given funding model.

- Targets been met in spite of SICAP, not because of it.

- Not working well as SICAP implementers are not working with other bodies as a partner but now overseen by so many other bodies.

- Conflict of interest arising in consistency regarding SICAP/LEADER/local authority.

- SICAP as core funding providing for other work to emerge.

- Some groups go from Stage 1 to Stage 3 - need more fluid matrix.

- Understanding on the ground: formal versus informal CD.

- Language of CD has been hijacked (qualitative versus quantitative).

- SICAP 2 now has three stages.

- It does not capture time involved. Costs not captured and lack of realism of the work involved.

- Getting beyond just registration PPN.

- Are best practice case studies being used well?

- Lack of understanding of creative approval needed to do the work.

- Where is $C D$ within partnership consultation? Where is the ethos?

- Concerns regarding the impact of competitive tendering process on CD work and organisations.

- Impact of the individual on group dynamics/capacity.

- Community groups' regeneration not captured. 
- Involvement in LCG should not be a life sentence.

- Staff versus management capacity-building maintenance.

- Case-study approach raised benchmark against indicators.

- Qualitative matrix is needed.

- Accessing groups and which stage they work on to make overall progress.

D. How can we improve the existing approach to data collection in order to more accurately reflect changes in community development in areas supported by SICAP?

- IRIS doesn't include outreach, pre-development, etc. - most of the work that you do.

- Progression doesn't make much sense - not always necessary for groups to progress and doesn't reflect the amount of work that goes into achieving progression.

- If we have IRIS, why do we need other forms of recording?

- No room for more general groups.

- Groups don't always go forward - sometimes go back - not an indicator of failure.

- Doesn't measure advocacy, resources that go into groups.

- Not counting the development work that it takes to get the groups into place in the first place.

- IRIS is very quantitative and needs to be more qualitative - not articulating the work that goes on.

- Need CD-style indicators and need to be part of the evaluation process rather than an add-on.

- There is a need to focus on a distance-travelled tool for LCGs, but needs to replace other sources of data collection that are not working.

- Pobal maps and the associated data could be improved and expanded using Census information.

- Framework needs to be developed from what we do, not Pobal coming along with a measure and providers expected to work towards it.

- Evaluations need to reflect what is valuable to communities rather than what is valuable to funders.

- The contextual information needs to be included as part of the evaluation process, appreciating the challenges associated with working with particular groups, e.g. Roma. 
- IRIS does not capture respect, inclusion, empowerment and equality - the factors that are important to $C D$.

- IRIS doesn't include consultations, feedback, door-to-door work, pre-development work that goes on.

- Don't want more time on IRIS as have limited time - this reduces time to do actual community work.

- One intervention tick means you got to next stage - not realistic! Huge work to get between stages which is not captured on IRIS. One group could be at multiple stages.

- Groups themselves are a collection of individuals. Value of groups to develop other work is not captured.

- Progression is not linear - should not be seen as failing.

- Want a hard and soft file - why not just one? (Having both is crazy.)

- No space for very general community groups - now have to have very specified groups.

- Measuring progress not $\mathrm{CD}$. Work to support those within a group is not captured.

- SICAP sees membership in groups as equal but leaders within - if you lose them the group falls apart.

- What is going on within the group is very different - some natural progression of groups is just sustainability

- IRIS doesn't measure much of what CWs do-advocacy; need more on process, resources for groups.

- Two interventions allow for gaming the system.

- We should be counting the interventions rather than the number of groups. Should weight the hard-to-reach groups as they are hard to work with and get the same weight.

- Sector decimated in budget cuts. A lot of groups gone - increased governance issues increasing - onus now on volunteers.

- Clarity regarding funding - trying to support groups' context, needs to support work.

- Most group work needs other programmes to work, such as volunteers programme. IRIS doesn't capture impact of other programmes or leverage.

- The wider context - disadvantaged groups don't get measured

- Every programme has very different ways of measuring.

- What measures don't need: duplication of data input (hard and soft); value case studies more/story of development; indicators mainly progression rather than actions. 
- IRIS is very quantitative. Reporting annually, timeframe is too short - work takes long time.

- If a large community group with a lot of groups attends, how do you record that?

- Lack of investment on CD training. Pobal used to bring groups together more.

- Qualitative instead of quantitative; want tool to reflect CD, distance-travelled tool.

- Case studies, progression should be core and not add-ons as add-ons don't get to the focus.

- A lot of stuff is not getting measured. IRIS doesn't capture volume of work or what you are actually doing.

- Ethnicity, family structure is not on HP Pobal maps.

- Stages are not linear.

- Increase in targets leads to superficial work and to a focus on less than 'hard-to-reach' groups.

- The measure should be assessed from what they do rather than coming along after.

- Need to develop what communities need.

- Can only measure CW if in a 'group' - a lot of work not being measured; nothing on system to count or measure e.g. relationship-building.

- IRIS volume of reporting so high. Often only record two interventions because of time it takes to manage IRIS and paper files.

- IRIs group information minimal - stages? Not meaningful. Need to develop better measures such as 'distance-travelled tool'.

- Good information is out there but more is needed, such as ethnicity.

- How to measure complexity for groups?

- IRIS should focus on reports. Could record number of hours worked with group.

- Only doing what the funder wants - should work from what we do and not from framework.

- Too many systems being used - departments need to co-ordinate.

- How does a group fill a data confidential form for other people? This is nonsense/legally dubious. How can an individual 'consent' for a group?

- Do what the group wants - might not want progression.

- No space to impart valuable information. SICAP language means nothing to communities. 
- The language should be used that is used with communities - at the moment the language is different for workers and then changed when they talk to community groups.

- IRIS doesn't capture respect, inclusion, support, inequality, listening.

- Assumes 'groups' are there - that this work doesn't need to be developed.

- Framework is useful but not as a measure.

- Structural barriers must be measured - empowerment, social change, anti-poverty, social inclusion, environment.

- Information is there to hit targets not to understand changes in CD. Only to be accountable to funders, not valuable to communities. Downward accountability. Should be accountable to communities.

- National-level thematic studies. Local case studies on a theme should be a requirement of PIs. 
Whitaker Square,

Sir John Rogerson's Quay, Dublin 2

Telephone +35318632000

Email admin@esri.ie

Web www.esri.ie

Twitter @ESRIDublin

ISBN 978-0-7070-0468-6 